Research Paper

\title{
Tagitinin $C$ induces ferroptosis through PERK-Nrf2-HO-1 signaling pathway in colorectal cancer cells
}

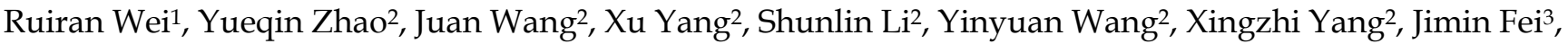 \\ Xiaojiang $\mathrm{Hao}^{2}$, Yuhan $\mathrm{Zhao}^{2 \bowtie}$, Liming Gui ${ }^{1 凶}$ and Xiao Ding ${ }^{2 \bowtie}$ \\ 1. Center for Tissue Engineering and Stem Cell Research, Guizhou Medical University, 550004, Guiyang, China. \\ 2. State Key Laboratory of Phytochemistry and Plant Resource in West China, Kunming Institute of Botany, Chinese Academy of Sciences, 650201, Kunming, \\ China. \\ 3. Yunnan Cancer Hospital \& The Third Affiliated Hospital of Kunming Medical University, 650118, Kunming, China. \\ $\triangle$ Corresponding authors: zhaoyuhan@mail.kib.ac.cn (Y.Z.); guiliming@gmc.edu.cn (L.G.); dingxiao@mail.kib.ac.cn (X.D.).
}

(C) The author(s). This is an open access article distributed under the terms of the Creative Commons Attribution License (https://creativecommons.org/licenses/by/4.0/). See http://ivyspring.com/terms for full terms and conditions.

Received: 2021.02.18; Accepted: 2021.06.08; Published: 2021.06.26

\begin{abstract}
Rationale: Colorectal cancer (CRC) is a common malignant tumor of the digestive system. However, the efficacy of surgery and chemotherapy is limited. Ferroptosis is an iron- and reactive oxygen species (ROS)-dependent form of regulated cell death (RCD) and plays a vital role in tumor suppression. Ferroptosis inducing agents have been studied extensively as a novel promising way to fight against therapy resistant cancers. The aim of this study is to investigate the mechanism of action of tagitinin $\mathrm{C}$ (TC), a natural product, as a novel ferroptosis inducer in tumor suppression.

Methods: The response of CRC cells to tagitinin $C$ was assessed by cell viability assay, clonogenic assay, transwell migration assay, cell cycle assay and apoptosis assay. Molecular approaches including Western blot, RNA sequencing, quantitative real-time PCR and immunofluorescence were employed as well.

Results: Tagitinin C, a sesquiterpene lactone isolated from Tithonia diversifolia, inhibits the growth of colorectal cancer cells including HCT116 cells, and induced an oxidative cellular microenvironment resulting in ferroptosis of HCT116 cells. Tagitinin C-induced ferroptosis was accompanied with the attenuation of glutathione (GSH) levels and increased in lipid peroxidation. Mechanistically, tagitinin C induced endoplasmic reticulum (ER) stress and oxidative stress, thus activating nuclear translocation of nuclear factor erythroid 2-related factor 2 (Nrf2). As a downstream gene (effector) of Nrf2, heme oxygenase-1 (HO-1) expression increased significantly with the treatment of tagitinin $\mathrm{C}$. Upregulated $\mathrm{HO}-1$ led to the increase in the labile iron pool, which promoted lipid peroxidation, meanwhile tagitinin $C$ showed synergistic anti-tumor effect together with erastin.

Conclusion: In summary, we provided the evidence that tagitinin $C$ induces ferroptosis in colorectal cancer cells and has synergistic effect together with erastin. Mechanistically, tagitinin $C$ induces ferroptosis through ER stress-mediated activation of PERK-Nrf2-HO-1 signaling pathway. Tagitinin C, identified as a novel ferroptosis inducer, may be effective chemosensitizer that can expand the efficacy and range of chemotherapeutic agents.
\end{abstract}

Key words: ferroptosis; tagitinin C; ROS; ER stress; Nrf2-HO-1 pathway

\section{Introduction}

Colorectal cancer is the fourth most common cancer cause of death globally, with about 2, 000, 000 new cases and 600, 000 deaths per year. The recorded incidence of colorectal cancer has been on the increase in developed countries [1]. Unlike other cancers, such as lung cancer, there is no single risk factor for colorectal cancer. Epidemiological studies have identified that many factors have contributed to this increase, such as age and sex, inflammatory bowel disease, lifestyle or environmental changes [2]. A total 
mesorectal excision is standard surgical procedure for the treatment of colorectal cancer, however, that radical surgery and chemotherapy lead to severe side effects, such as reduced immune function and reduction in quality of life. And immunotherapy has been applied to a subset of colorectal cancers, with median progression-free survival (PFS) rate of $61 \%$ and overall survival (OS) rate of $66 \%$ at 24 months [3]. So far, over half of all sufferers do not survive for longer than 5 years after diagnosis, despite it being curable if diagnosed early. In the clinic, to integrate novel targeted therapeutic agents into standard therapy is key for increasing the survival of patients and improving overall quality of life. This necessitates further insight into colorectal cancer and discovery of new drug(s) [4].

Ferroptosis is an iron- and ROS-dependent programmed cell death that is distinct from apoptosis, autophagy, and necrosis at morphological, biochemical, and genetic levels [5,6]. Emerging studies have discovered that ferroptosis is a new therapeutic strategy to overcome the drug resistance in cancer cells $[7,8]$. Whether as monotherapy or in combination with other chemotherapeutic drugs, ferroptosis inducers can induce ferroptosis in cancer cells, especially in drug-resistant cancer cells [9]. In addition, ferroptosis can selectively target aggressive cancer stem cells and is also expected to enhance the efficacy of immunotherapy and overcome the resistance to immunotherapy [10,11]. Erastin is a ferroptosis inducer that functionally inhibits cystineglutamate reverse transporter (System Xc-). Cystine uptake would be inhibited by erastin, which leads to deprivation of the antioxidant glutathione and eventually oxidative cell death $[12,13]$.

Ample studies have suggested that some natural plant extracts show significant antitumor effect through ferroptosis, including artemisinim, amentoflavone, ruscogenin, gallic acid, dihydroisotanshinone I and so on [14-19]. Tagitinin C is a sesquiterpene lactone which is widely found in Asteraceae [20]. It has increasingly attracted the interests of researchers because of its various pharmacological activities including antitumor, antiviral, antifibrotic, antiparasitic and cardioprotective effects [21-23]. It has been reported that tagitinin $\mathrm{C}$ induces the cell death through triggering autophagy in human glioblastoma cells [24]; and in hepatocellular carcinoma (Hep-G2), tagitinin C arrests the cell cycle at sub-G1 and $S$ phase and induces apoptosis [25].

Herein, we found that tagitinin $C$ has the ability to activate ferroptosis pathway in the colorectal cancer cells. Previous reports have pointed out some tumor cell lines were insensitive to ferroptotic inducers [26]. In line with this, our experiments showed that colorectal cancer line HCT116 cells were insensitive to erastin-induced ferroptosis. We therefore used these cells to explore the feasibility that tagitinin C could induce and/or enhance the incidence of ferroptosis and elucidate its mechanism. Our results demonstrated that cell viability of HCT116 cells was significantly reduced by tagitinin C. Evidence of ferroptosis features in tagitinin $\mathrm{C}$ treated cells, including a high production of ROS and lipid peroxidation. Mechanistically, tagitinin $C$ induced ferroptosis through ER stress-mediated PERK-Nrf2HO-1 signaling pathway. The combination of tagitinin $\mathrm{C}$ and erastin synergistically activated ER stress and enhanced ferroptosis. Our current study sheds light on development of a potential treatment strategy for CRC, especially chemoresistant CRC, with combinational therapy including tagitinin $\mathrm{C}$.

\section{Materials and Methods}

\section{Cell culture}

CRC cell lines were cultured in DMEM or RPMI1640 (Gibco, Thermo Fisher Scientific, Germany) supplemented with $10 \%$ fetal bovine serum (Gibco, Thermo Fisher Scientific, Germany), 1\% antibiotics (penicillin $10000 \mathrm{U} / \mathrm{ml}$, streptomycin $100 \mathrm{mg} / \mathrm{ml}$ ) (Solarbio, Beijing, China). The cells were maintained at $37{ }^{\circ} \mathrm{C}$ in a humidified atmosphere of $5 \% \mathrm{CO}_{2}$, and were used during their logarithmic growth phase.

\section{Cell viability assay}

The cytotoxicity caused by tagitinin $\mathrm{C}$ was measured by the 3-(4,5-dimethylthiazol-2-yl)-2, 5-diphenyltetrazolium bromide (MTT) assay (Meilunbio, Dalian, China) or CCK-8 assay (APE $\times$ BIO, USA). Cells were seeded in 96-well plates in 100 $\mu \mathrm{L}$ medium. $20 \mu \mathrm{L}$ MTT or $10 \mu \mathrm{L}$ CCK-8 solution were added to each well and incubated at $37^{\circ} \mathrm{C}$ for $4 \mathrm{~h}$. The absorbance at 490 or $450 \mathrm{~nm}$ were measured on a spectrophotometer.

\section{Clonogenic assay}

500 cells/well were seeded into a 6-well plate and treated for 14 days with tagitinin C. Then the clones were stained with $1 \%$ crystal violet solution (Solarbio, Beijing, China) for $30 \mathrm{~min}$. After washing with PBS for three times, the colonies were imaged by the camera and quantified. For estimation of the number of colonies formed, crystal violet was dissolved in $100 \%$ methanol, transferred to a 96-well plate, diluted 1:10 using PBS and absorbance was measured at $540 \mathrm{~nm}$ using spectrophotometer. 


\section{Transwell migration assay}

Cell migration was examined by a transwell chamber apparatus (24-well plates, 8- $\mu \mathrm{m}$ pore size. Corning Incorporated Costar, USA). Briefly, the lower chamber was filled with $750 \mu \mathrm{l}$ RPMI-1640 containing $10 \%$ FBS. A total of $2 \times 10^{4}$ cells in $200 \mu \mathrm{L}$ serum-free RPMI-1640 were seeded in the upper well and were respectively incubated with tagitinin $\mathrm{C}$ for $24 \mathrm{~h}$ at 37 ${ }^{\circ} \mathrm{C}$. Migrated cells were fixed with $4 \%$ paraformaldehyde and stained with $1 \%$ crystal violet. Images were captured using a microscope and the migrated cells were counted.

\section{Annexin V-FITC-propium iodide assay}

An Annexin V-FITC apoptosis kit (Meilunbio, Dalian, China) was used to determine the number of apoptotic cells according to the manufacturer's instructions. Briefly, cells were grown in 6-well plates. When the cells reached $80-90 \%$ confluence, different treatments were applied to the cells. The cells were then harvested, washed twice with ice-cold PBS and resuspended in $400 \mu \mathrm{L}$ of binding buffer. Then, $5 \mu \mathrm{L}$ Annexin $\mathrm{V}$ and $5 \mu \mathrm{L}$ propidium iodide were added and the mixture was incubated in the dark at $37^{\circ} \mathrm{C}$ for $30 \mathrm{~min}$. A total of 10,000 events per sample were analyzed. Annexin V positivity was calculated with a FACS Calibur flow cytometer using Flowjo V10 software.

\section{Cell cycle assay}

Cell Cycle Analysis Kit (Meilunbio, Dalian, China) was used to analyze cell cycle after treating with different concentration of tagitinin $C(5,10,20$ $\mu \mathrm{M})$ according to the manufacturer's protocol. Briefly, cells were fixed by $70 \%$ ethanol at $-20{ }^{\circ} \mathrm{C}$ for overnight, and washed with PBS for three times and stained with staining solution of the kit supplemented with $200 \mathrm{mg} / \mathrm{ml}$ RNase at $37^{\circ} \mathrm{C}$ for $30 \mathrm{~min}$ in the dark. Then cell cycle rates were measured by flow cytometry and the percentage of cells at G0/G1, S, or G2/M phase were quantified.

\section{Measurement of lipid peroxidation}

The total cellular lipid peroxidation was measured using a C11 BODIPY (581/591) probe (Cayman Chemical, USA). Cells were treated as indicated and when then incubated for $1 \mathrm{~h}$ at $37^{\circ} \mathrm{C}$ with C11 BODIPY $(2 \mu \mathrm{M})$ in fresh medium. Excess C11 BODIPY was removed by washing the cells twice with PBS. Labeled cells were then trypsinized and resuspended in PBS for flow cytometry analysis. Oxidation of the polyunsaturated butadienyl portion of C11 BODIPY resulted in a shift of the fluorescence emission peak from $\sim 590 \mathrm{~nm}$ to $\sim 510 \mathrm{~nm}$ proportional to lipid peroxidation generation and was analyzed using a flow cytometer (BD Biosciences, US).

\section{Measurement of malondialdehyde (MDA)}

Cell malondialdehyde (MDA) assay kit (Beyotime, Shanghai, China) was used to measure cellular MDA contents based on thiobarbituric acid (TBA) reactivity. Briefly, HCT116 cells were seeded into 6-well plates and cultured overnight. After treated as indicated, cells were harvested and lysed. Then, after protein quantification of the lysate, MDA working solution was added and heated at $100{ }^{\circ} \mathrm{C}$ for 15 min. Next, the supernatant was collected after centrifuging at $1000 \mathrm{rpm}$ for $10 \mathrm{~min}$ at $4{ }^{\circ} \mathrm{C}$, and then measured at $532 \mathrm{~nm}$ with a microplate reader. The relative cellular MDA concentration was presented as percentage of control.

\section{Determination of the labile iron pool}

The total cellular labile iron pool was detected based on the calcein-acetoxymethyI ester (C-AM) method. After trypsinization, the cells were washed twice with PBS followed by incubation of $2 \mu \mathrm{M}$ calcein-acetoxymethyI ester (GLPBIO, USA) for 30 min at $37^{\circ} \mathrm{C}$. Then, the cells were washed with PBS and incubated with or without deferoxamine $(5 \mu \mathrm{M})$ for $1 \mathrm{~h}$ at $37^{\circ} \mathrm{C}$. The cells were analyzed by flow cytometry or SpecttaMax iD3. Calcein was excited at $488 \mathrm{~nm}$, and fluorescence was measured at $525 \mathrm{~nm}$. The levels of the labile iron poor were calculated by the difference in cellular mean fluorescence with and without deferoxamine incubation.

\section{Measurement of ROS}

DCFH-DA (Meilunbio, Dalian, China) was used to detect the ROS levels according to the manufacturer's protocol. In brief, cells were seeded in 6-well plates and cultured with tagitinin C. After treatment, cells were harvested and washed twice with PBS and labeled with $20 \mu \mathrm{M}$ DCFH-DA under 37 ${ }^{\circ} \mathrm{C}$ for $30 \mathrm{~min}$ in the dark, cells were then collected and the fluorescence intensity of DCF was tested by SpectraMax iD3 or flow cytometry (BD Biosciences, US).

\section{Measurement of glutathione}

Glutathione was measured using monochlorobimane (MCB) (Sigma-Aldrich, USA). The cells were plated in a black 96-well plate and treated with tagitinin $\mathrm{C}$. Then cells were incubated for 30 minutes at $37{ }^{\circ} \mathrm{C}$ with MCB $(32 \mu \mathrm{M})$ in PBS. Fluorescence was measured using SpecttaMax iD3 with excitation set at $390 \mathrm{~nm}$ and emission set at 478 nm. 


\section{Mitochondrial membrane potential $(\Delta \Psi M)$ assay}

Mitochondrial membrane potential $(\Delta \Psi \mathrm{m})$ was measured using TMRE (MCE, Shanghai, China). In brief, when the $\Delta \Psi \mathrm{m}$ is high, TMRE gathers in the mitochondria and produces red-orange fluorescence. HCT116 cells were seeded in 96-well plates and treated with tagitinin $C$. Then cells were incubated for 30 minutes at $37{ }^{\circ} \mathrm{C}$ with TMRE $(1 \mu \mathrm{M})$ in PBS. Fluorescence intensity was measured by microplate reader (Bio-Rad, Shanghai, China). The excitation wavelength was $540 \mathrm{~nm}$, and the emission wavelength was $595 \mathrm{~nm}$.

\section{Western blot analysis}

Cells were collected and then lysed on ice for 30 min using radioimmunoprecipitation assay (RIPA) buffer (Meilunbio, Dalian, China). Equal amounts of cell lysates were subjected to electrophoresis in SDS-PAGE gel and transferred into PVDF transfer membranes for antibody blotting. The membranes were blocked with $5 \%$ nonfat dry milk for $1 \mathrm{~h}$ at room temperature (RT) and incubated with antibodies against ER stress-related proteins (Cell Signaling Technology, Germany), Nrf2 and HO-1 (Abcam, USA) overnight at $4{ }^{\circ} \mathrm{C}$, and then incubated with horseradish peroxidase-conjugated secondary antibody for $1 \mathrm{~h}$. The ECL reagent was used for detecting target bands.

\section{Quantitative real-time polymerase chain reaction (qPCR)}

Total RNA was extracted from cells by TRIzol. Reverse transcription was carried out according to the manufactures' direction. Real-time PCR was carried out using SYBR GreenER qPCR superMix Universal and the A100 PCR system. Sequences of real-time PCR (qPCR) primers: Nrf2: 5'-CACATCCAGTCAGAAAC CAGTGG-3' and 5'-GGAATGTCTGCGCCAAAAG CTG-3'; HO-1: 5'-5'-AAGACTGCGTTCCTGCTC AAC-3' and 5'-AAAGCCCTACAGCAACTGTCG-3'; POR: 5'-GGTGGCCGAAGAAGTATCTCT-3' and 5'AACCAGTAGGTTAGGAGACCC-3'; GPX4: 5'-GAG GCAAGACCGAAGTAAACTAC-3' and 5'-CCGAAC TGGTTACACGGGAA-3'; FSP1: 5'-AGACAGGGTTC GCCAAAAAGA-3' and 5'-CAGGTCTATCCCCACTA CTAGC-3'; Actin: 5'-GATCTGGCACCACACCT TCT-3' and 5'-GGGGTGTTGAAGGTCTCAAA-3'.

\section{Immunofluorescence}

HCT116 cells were plated on coverslips and treated with $20 \mu \mathrm{M}$ tagitinin C. Immunofluorescence was performed as the recommended protocol. Briefly, after washing twice in PBS, cells were fixed in methanol for $5 \mathrm{~min}$ at RT. After fixation, cells were washed three times in PBS for 5 min and treated with a blocking solution (1\% BSA in PBS) for $30 \mathrm{~min}$. Subsequently, the cells were washed twice in PBS and incubated with the primary antibody directed against Nrf2 (anti-rabbit, Abcam, USA) overnight at $4{ }^{\circ} \mathrm{C}$. Then, cells were washed three times in PBS for $5 \mathrm{~min}$ and incubated for $2 \mathrm{~h}$ with a conjugated secondary antibody, goat anti-rabbit IgG-Cy3 (Thermo Fisher Scientific, USA). Nuclei were stained with DAPI Stain Solution. The images were captured using a Leica Confocal Microscope TCS SP8 (Leica Microsystems).

\section{Statistical analysis}

All experiments were conducted at least three times, and the data are presented as the mean \pm SD. Statistical significance among different treatments were determined by student's $t$-test. A $p$ value $<0.05$ was considered to be statistically significant.

\section{Results}

\section{Tagitinin C suppresses cell growth and induces cell death}

The chemical structure of tagitinin $\mathrm{C}$ is shown in Figure 1A. To determine the cytotoxic effect of tagitinin $\mathrm{C}$ on the proliferation of CRC cell lines, we treated colorectal cancer SW480 (Figure 1B), DLD1 (Figure 1C), and HCT116 (Figure 1D) cell lines with different concentrations of tagitinin $C$ for 12, 24, 48, 72 $\mathrm{h}$ and assessed cell viability via MTT assay. The results showed that tagitinin $\mathrm{C}$ significantly reduced the viability of these three types of CRC cell lines in a concentration- and time-dependent manner compared to the untreated cells. Under microscopy, morphology of SW480 cells, DLD1 cells, and HCT116 cells were shattered, amorphous and multidirectional after tagitinin $C$ treatment for different time points, which showed that tagitinin $C$ treatment led to cell death of SW480, DLD1 and HCT116 cells (Figure 1E). In HCT116 cells, higher cell confluence conferred resistance to ferroptosis [27], however, we found that the HCT116 cell line is insensitive to erastin-induced ferroptosis (Figure S1A). Thus, we chose HCT116 cells for further study.

\section{Tagitinin $C$ inhibits colony formation, cell migration abilities and induces $\mathbf{G} 2 / \mathrm{M}$ phase cell cycle arrest in HCT116 cells}

We next investigated the effect of tagitinin $C$ on colony formation in HCT116 cells by clonogenic cell survival assay [28-30]. As shown in Figure 2A-B, tagitinin $C$ induced a significant concentrationdependent reduction in the number of colonies after 14 days treatment. The results indicated that tagitinin C significantly inhibited the clonogenic growth of HCT116 cells. Transwell migration assay was 
employed to investigate the effect of tagitinin $\mathrm{C}$ on cell migration ability of HCT116 cells (Figure 2C-D). The results suggested that tagitinin $\mathrm{C}$ significantly inhibited cell migration in a dose-dependent manner.

Further, we examined the effect of tagitinin $C$ on cell cycle by flow cytometry. As shown in Figure 2E-F, significant changes in cell cycle were observed in

A<smiles>C=C1C(=O)C=CC=C(C)/C=C\OC1=O</smiles>

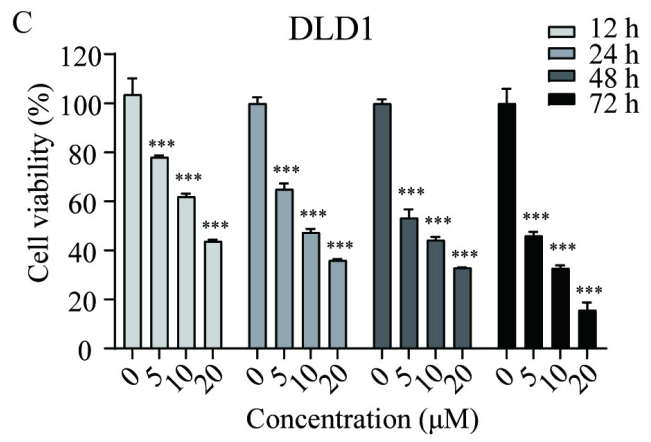

$\mathrm{E}$

SW480
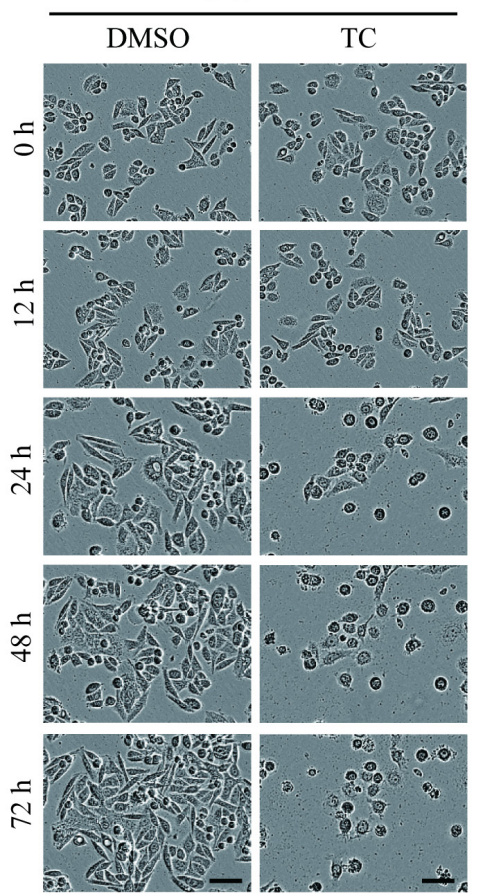

HCT116 cells. As compared with control group, cells were arrested at G2/M phase in a dose-dependent manner. These data indicated that tagitinin $\mathrm{C}$ induced G2/M cell cycle arrest in HCT116 cells and might suppress the proliferation of cells by inducing cell cycle arrest.
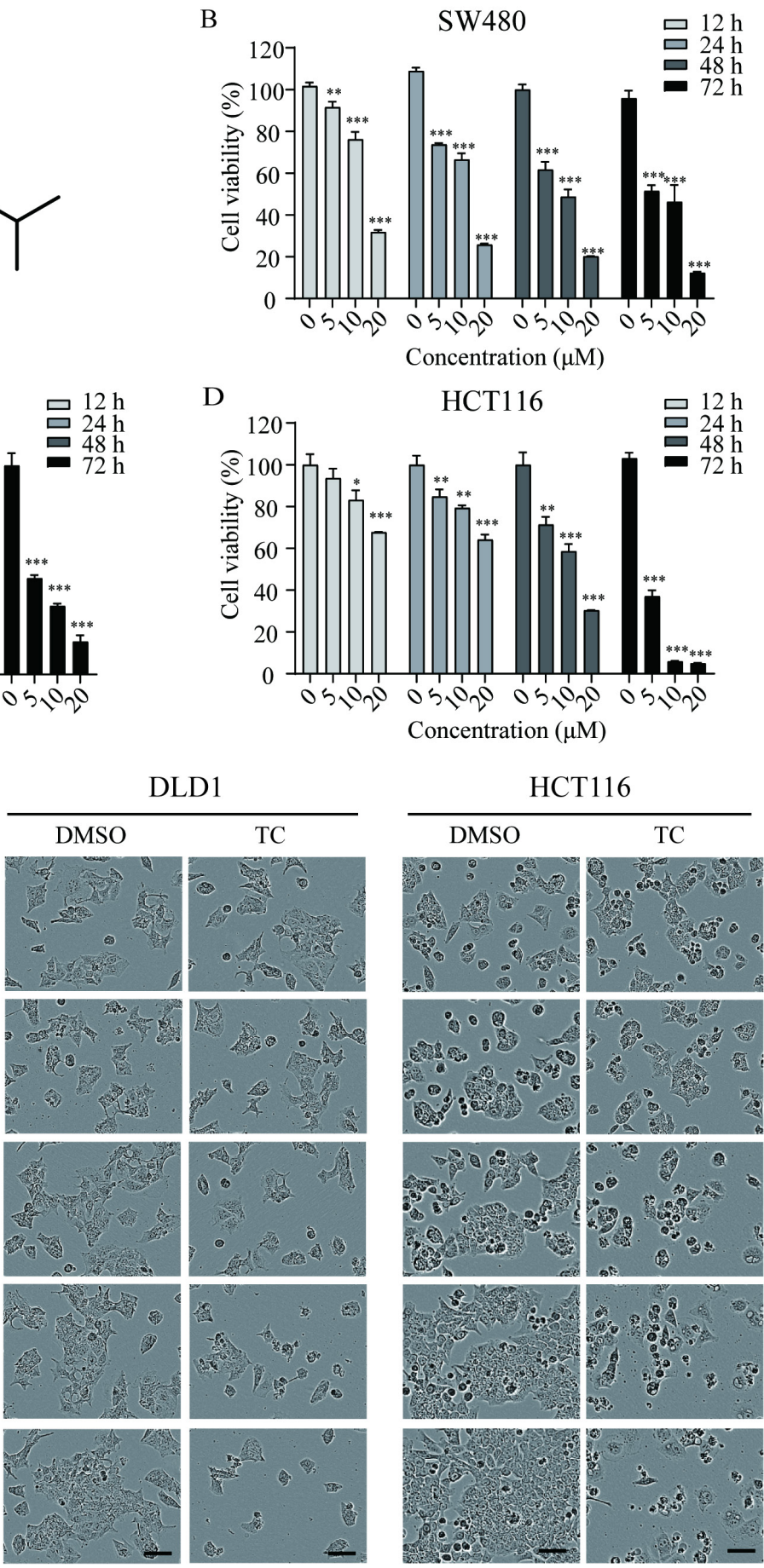

Figure 1. Tagitinin C suppresses cell growth and induces cell death. (A) The chemical structure of tagitinin C. (B-D) Cell viability of SW480, DLD1, and HCT116 cells were measured by MTT assay after treatment with indicate concentration of tagitinin C $(5,10,20 \mu \mathrm{M})$ at $12,24,48,72 \mathrm{~h}$. (E) Cell morphology of SW480, DLD1, and HCT116 after treatment with concentration of tagitinin $\mathrm{C}(20 \mu \mathrm{M})$ at $0,12,24,48$, and $72 \mathrm{~h}$ (magnification, $\times 10)$. Data were presented as Mean \pm SD. Scale bar indicates $40 \mu \mathrm{m}$. Statistical analysis was carried out between tagitinin C-treated group and DMSO group: $* p \leq 0.05$, ** $p \leq 0.01$, *** $p \leq 0.001$. 
A

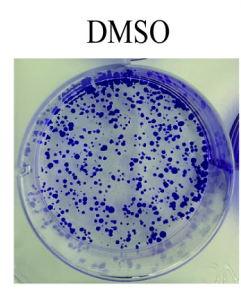

C

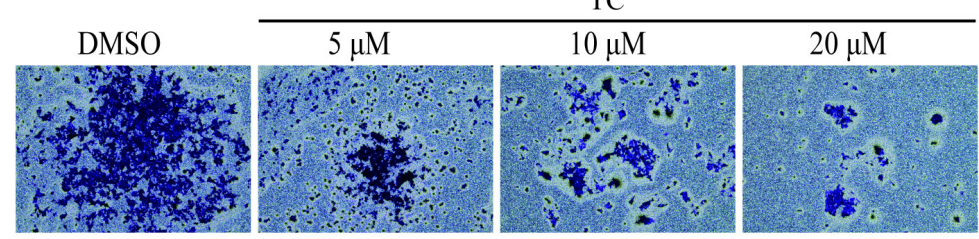

E

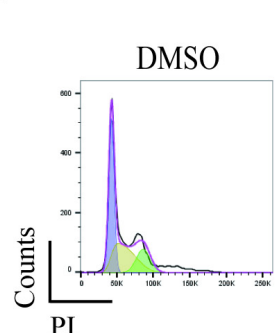

TC
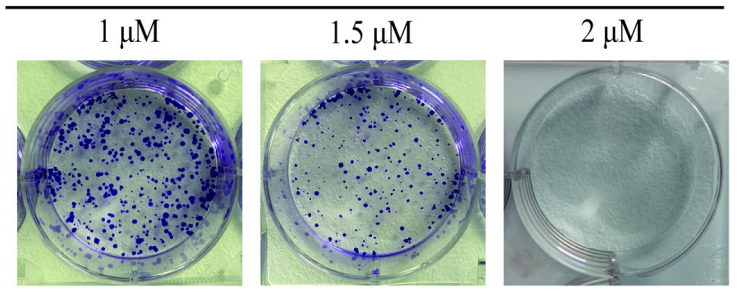

D
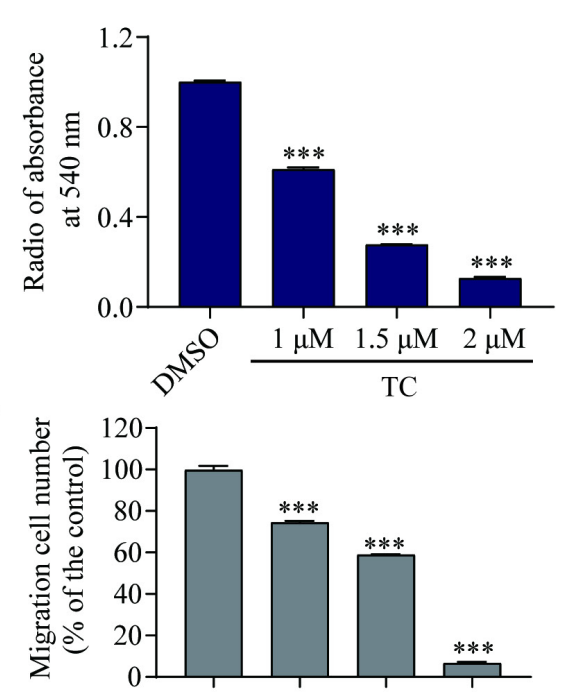

F
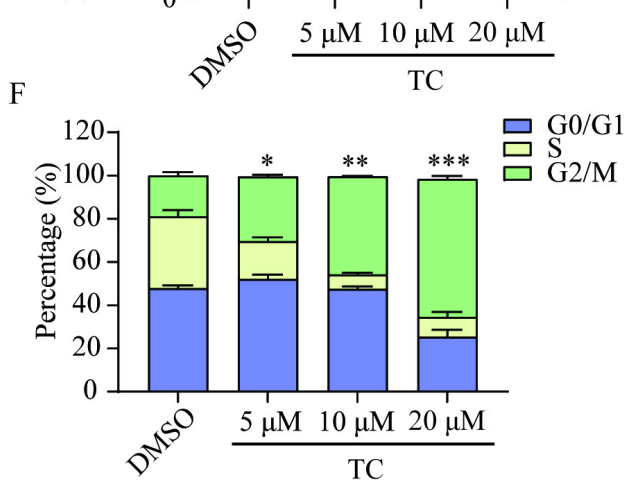

Figure 2. Tagitinin $\mathrm{C}$ inhibits the colony formation, cell migration abilities and induces G2/M cell cycle arrest in HCT116 cells. (A-B) Tagitinin C inhibited the colony formation ability of HCT116 cells in a dose-dependent manner. (A) Representative images of cell colonies after 14 days treatment tagitinin C (1, 1.5, $2 \mu$ M). (B) Bar graph shows the quantification of colonies numbers by measuring absorbance at $540 \mathrm{~nm}$. (C-D) Tagitinin C inhibited the migration ability of HCT1 16 cells. (C) Transwell migration assay was performed in HCT1 16 cells treated with tagitinin $\mathrm{C}(5,10,20 \mu \mathrm{M})$ and representative images were shown. (D) Quantitative analysis for number of migrated HCT116 cells. (E-F) Tagitinin C induced G2/M cell cycle arrest in HCT116 cells. Representative images (E) and quantifications of populations of HCT116 cells in the cell cycle (F) after cells were treated with increasing concentration of tagitinin $C(5,10,20 \mu \mathrm{M})$ for $24 \mathrm{~h}$. Data were presented as Mean \pm SD. Scale bar indicates $100 \mu \mathrm{m}$. Statistical analysis was carried out between tagitinin C-treated group and DMSO group: * $p \leq 0.05, * * p \leq 0.01, * * * p \leq 0.001$.

\section{Tagitinin C induces ferroptosis in HCT116 cells}

To investigate whether tagitinin $\mathrm{C}$ induces apoptosis as previously reported, the cell death was detected by flow cytometry analysis using Annexin V and PI staining (Figure 3A-B). Results showed that tagitinin C could induced apoptosis after 24 or 48 hours treatment. Interestingly, for short time treatment (12 hours) with tagitinin C in HCT116 cells, a portion of the cells gathered in the area of Annexin $\mathrm{V}^{-}$/ PI + (Figure 3A). This result suggested that tagitinin $C$ may have induced or may induce a different type of cell death other than apoptosis within 12 hours. To further investigate what kind of cell death was induced by tagitinin $C$ in this short time, different cell death inhibitors were tested together with tagitinin C. As shown in Figure 3C, tagitinin C-induced cell death was attenuated by the pharmacological ferroptosis inhibitors, Fer-1 (Ferrostatin-1) [31] and DFO (Deferoxamine) [32], but not by VAD (Z-VAD-FMK, apoptosis inhibitor), 3-MA (autophagy inhibitor) and Nec-1 (necrostatin-1, necroptosis inhibitor). This result indicated that tagitinin C-induced cell death within 12 hours is non-apoptotic and non-necroptotic cell death and might be the novel programmed cell death ferroptosis. However, Fer-1 and DFO cannot attenuate the cell death induced by tagitinin $\mathrm{C}$-induced cell death for longer than $24 \mathrm{~h}$ or longer time (Figure 3D), suggesting that tagitinin C-induced apoptosis might be dominant for longer time treatment. All these results indicated that tagitinin C-induced early cell death might be ferroptosis while apoptosis might be induced upon longer time treatment.

Lipid peroxidation, a key event of ferroptosis [33], was increased by tagitinin $\mathrm{C}$ at $12 \mathrm{~h}$, which was reversed partly by Fer-1 and DFO (Figure 3E), indicating that the addition of tagitinin $C$ enhanced lipid peroxidation. Similar results were observed with regard to the changes in the level of malondialdehyde (MDA) in HCT116 cells induced by tagitinin C (Figure $3 F)$. MDA is the most prevalent byproduct of lipid 
peroxidation [34]. It is known that intracellular iron contributes to the ferrous iron accumulation that leads to cell cytotoxicity via specific ROS generation [35], which is responsible for ferroptosis. Next, we assessed how tagitinin $C$ regulates cellular iron in HCT116 cells. Both free and chelatable iron is the so-called labile iron pool (LIP) [36]. LIP levels were upregulated by tagitinin $C$ at $12 \mathrm{~h}$ but significantly less so in the presence of Fer-1 (Figure 3G). Further, we found that after the tagitinin $C$ treatment within 12 hours, lipid peroxidation, MDA and LIP (Figure S1B-D) were up-regulated to various degrees. These results indicated that tagitinin C-induced HCT116 early cell death was accompanied with elevated lipid peroxidation, MDA and LIP, which are characteristic features of ferroptosis.

\section{Tagitinin C induces ROS generation, which contributes to mitochondrial dysfunction}

Ferroptosis depends on ROS production for its cytotoxicity [11,37]. To investigate the role of ROS in tagitinin C-induced ferroptosis, we first used the DCFH-DA probe to real-time monitor the total cellular ROS generation, and then used incucyte (Figure 4A) and flow cytometry (Figure 4B) to detect changes of fluorescence intensity after cells were treated with tagitinin $\mathrm{C}$. The results revealed that tagitinin $\mathrm{C}$ rapidly triggered ROS production in HCT116 cells in a time- and concentration-dependent manner, this phenotype can be efficiently reversed by an antioxidant, N-acetyl-L-cysteine (NAC) [38]. Fluorescence signals detected by microscopy were consistent with the above results (Figure 4C). NAC
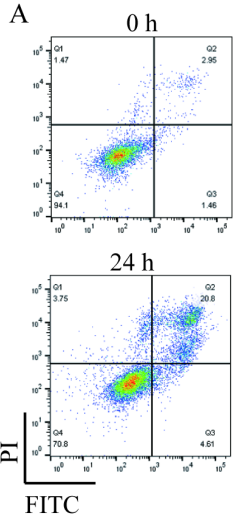

$\mathrm{D}$
B
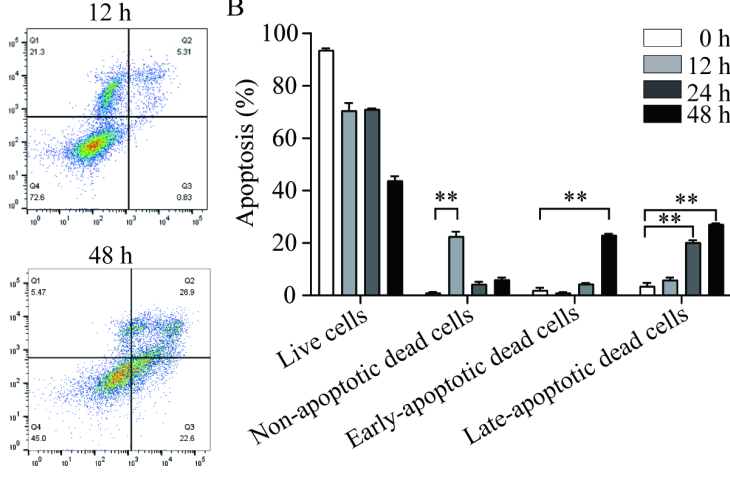

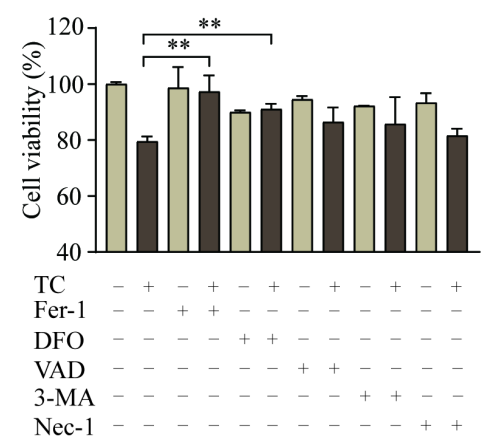

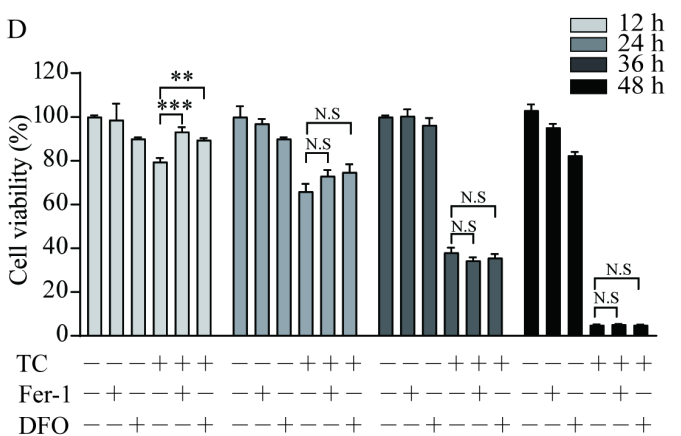

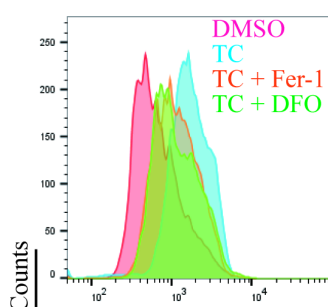

C11-BODIPY

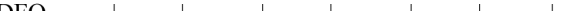

G

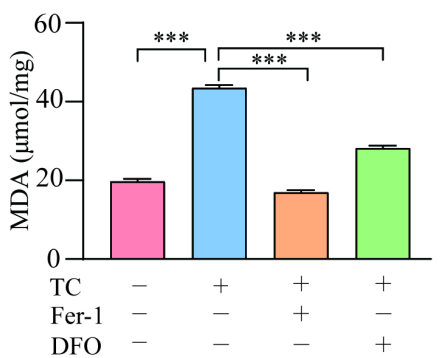

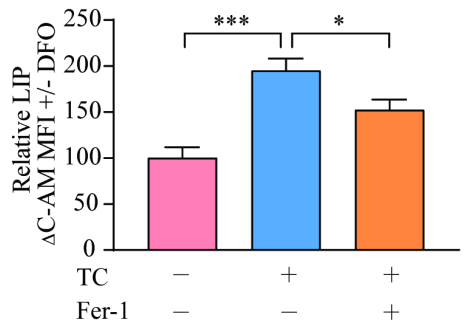

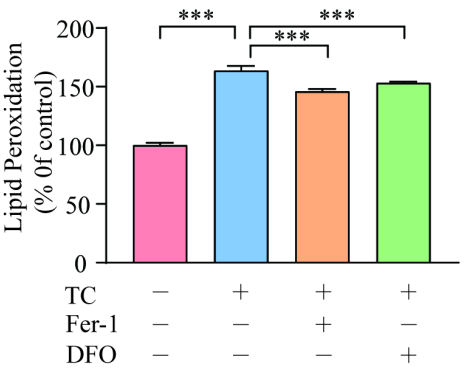

Figure 3. Tagitinin $\mathbf{C}$ induces ferroptosis in HCT116 cells. (A-B) Flow cytometric analysis of apoptosis in the HCT116 cells treated with tagitinin $\mathrm{C}$ ( $20 \mu \mathrm{M})$ after 0 , 12 , 24, $48 \mathrm{~h}$. Image (A) and quantitative analysis for apoptotic cells (B) were presented. (C) Cell viability was measured using CCK-8 assay in control cells and cells treated with tagitinin $C(20 \mu \mathrm{M})$ with or without Fer-1 $(1 \mu \mathrm{M})$, DFO $(5 \mu \mathrm{M})$, Z-VAD-FMK $(20 \mu \mathrm{M})$, 3-MA $(2 \mathrm{mM})$, and Nec-1 (50 $\mu \mathrm{M})$ at $12 \mathrm{~h}$. (D) Fer-1 (1 $\mu$ M) and DFO $(5 \mu \mathrm{M})$ rescued tagitinin C-induced cell death at $12 \mathrm{~h}$. (E) Fer-1 and DFO blocked tagitinin C-induced lipid peroxidation, quantified using C11-BODIPY lipid probe using flow cytometry in HCT116 cells. (F) Quantification of cellular MDA levels using the TBA method. (G) Quantification of cellular LIP levels using the calcein-AM (C-AM) method. The mean fluorescence intensity (MFI) of C-AM is subtracted from the MFI of C-AM treated with DFO. Data were presented as Mean \pm SD. Statistical analysis was carried out between tagitinin C-treated group and DMSO group: * $p \leq 0.05, * * p \leq 0.01, * * * \leq 0.001$. 
not only effectively inhibited the generation of ROS and subsequent lipid peroxidation, MDA and LIP (Figure 4D-F), but also rescued the cell death induced by tagitinin C in HCT116 cells at $12 \mathrm{~h}$ (Figure 4G).

GSH is an antioxidant that plays a crucial role in maintaining the redox balance and defending against oxidative stress (including ROS) in cells [39]. We evaluated intracellular GSH levels in HCT116 cells after treatment with tagitinin $\mathrm{C}$ within 12 hours. The results showed that GSH level was decreased within $12 \mathrm{~h}$ (Figure $4 \mathrm{H}$ ), and this decrease was also attenuated when cells were treated with the combination of tagitinin C and NAC (Figure 4I). In addition, ROS is a critical factor in maintaining
A
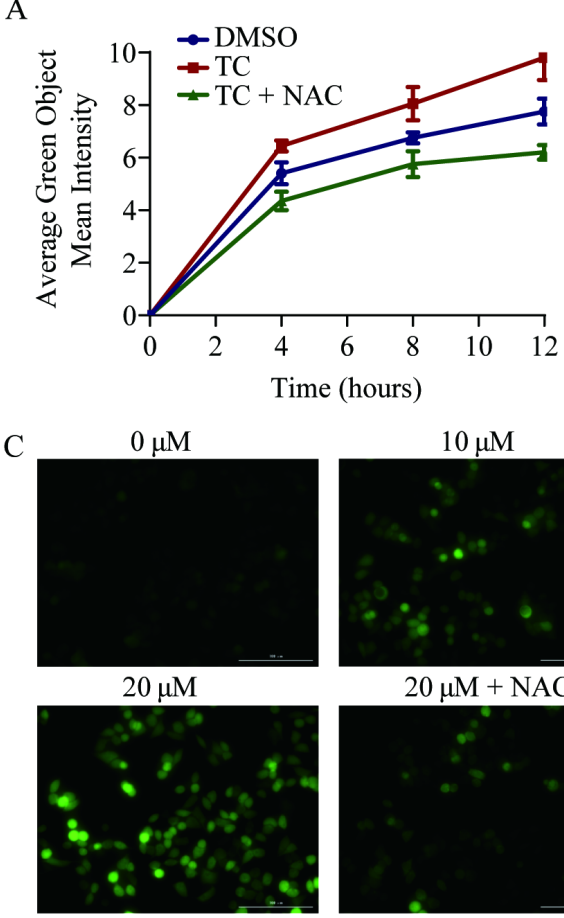

E

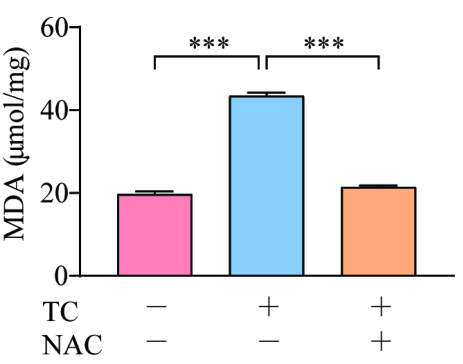

H

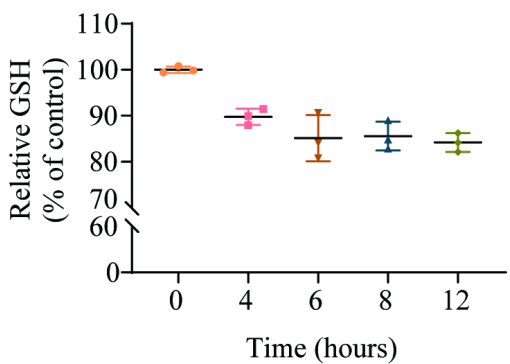

I
B

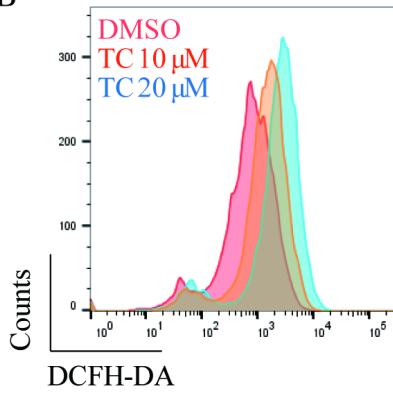

D
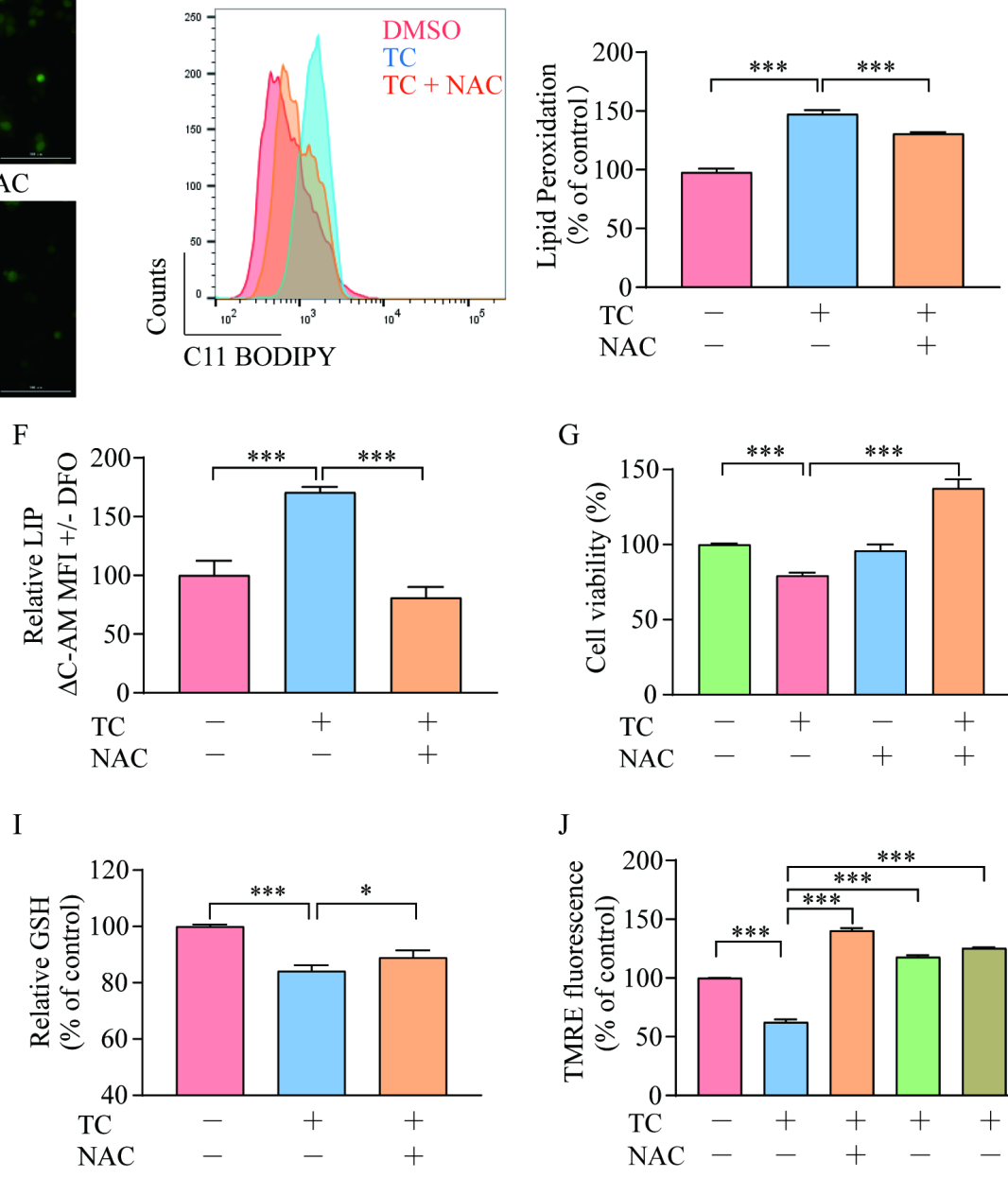

G
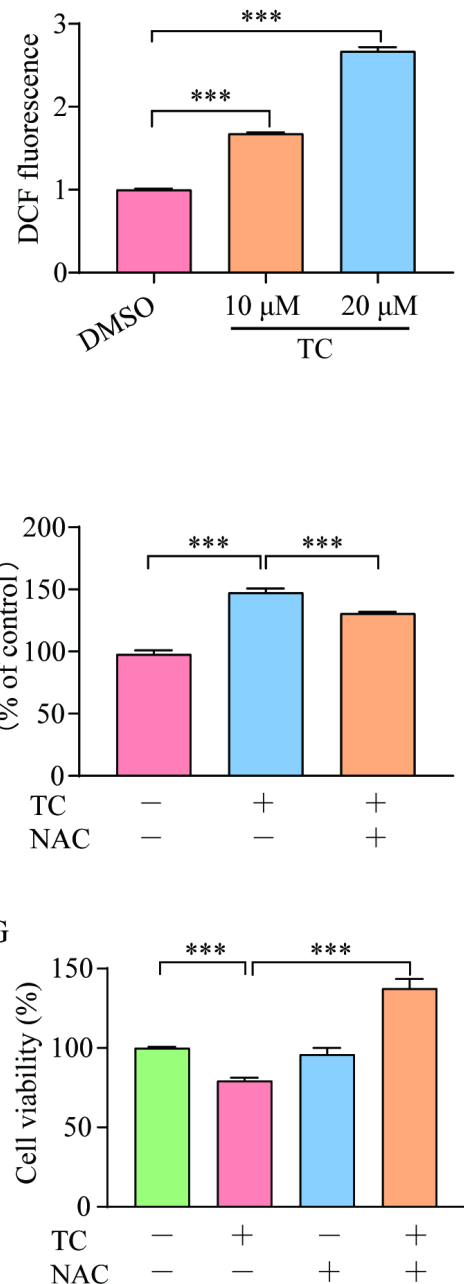

J

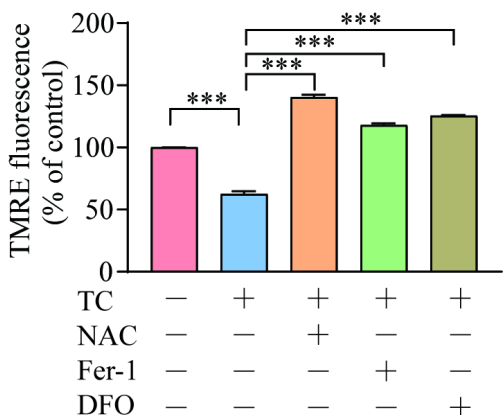

Figure 4. Tagitinin $\mathbf{C}$ induces ROS generation and contributes to mitochondrial dysfunction. (A-C) DCFH-DA probe was used to detected ROS levels in HCT116 cells by Incucyte S3 (A), flow cytometry (B) and fluorescence microscope (C) (magnification, $\times 20)$ respectively. (D-E) Tagitinin C (20 $\mu M$ ) increased the level of lipid peroxidation (D), MDA (E) and LIP (F), which could be blocked by NAC (200 $\mu$ M). (G) Cell viability was measured using CCK-8 assay in control cells and cells treated with tagitinin C with or without NAC $(200 \mu \mathrm{M})$ at $12 \mathrm{~h}$. (H) Quantification of the reduced cellular GSH levels using the MCB method. (I) Tagitinin C (20 $\mu$ M) decreased the level of $\mathrm{GSH}$, which could be blocked by NAC $(200 \mu \mathrm{M})$. (J) Tagitinin C $(20 \mu \mathrm{M})$ decreased the TMRE fluorescence in HCT116 cells, which could be blocked by NAC ( $200 \mu M)$, Fer-1 $(1 \mu \mathrm{M})$ and DFO $(5 \mu \mathrm{M})$. Data were presented as Mean \pm SD. Scale bar indicates $100 \mu \mathrm{m}$. Statistical analysis was carried out between tagitinin C-treated group and DMSO group: $* p \leq 0.05$, ** $p \leq 0.01$, *** $p \leq 0.001$. 
mitochondrial homeostasis. Mitochondrial membrane potential $(\Delta \Psi \mathrm{m})$ is often used to measure mitochondrial function, and a loss of $\Delta \Psi \mathrm{m}$ indicates mitochondrial dysfunction [40]. TMRE is a dye widely used in the detection of $\Delta \Psi \mathrm{m}$. Fluorescence intensity measured by microplate reader showed that TMRE fluorescence in HCT116 cells discreased with tagitinin $\mathrm{C}$ treatment, and this decrease was also attenuated when cells were treated with the combination of tagitinin C and NAC, Fer-1 and DFO (Figure 4J). This result indicated that a loss of $\Delta \psi \mathrm{M}$ was caused by tagitinin $\mathrm{C}$ and might result in dysfunction of mitochondria.

\section{Tagitinin C activates Nrf2-HO-1 signaling pathway}

In order to investigate the underlying mechanism of tagitinin C-induced ferroptosis, RNA-sequencing analysis was employed. We found that tagitinin C-mediated oxidative stress involved the activation of the Nrf2 signaling pathway (Figure $5 \mathrm{~A})$. Nrf2, is a well-known upstream element of the genes that are up-regulated in response to ROS [41] and ER stress [42,43]. Nrf2 is a transcription factor and phosphorylated Nrf2 translocates into the nucleus to transactivate its target genes, including HO-1, GCLM, GCLC, SLC7A11, FTH1, ATF6, NQO1, ATF3, and GAPDH, as well as Nrf2 itself. Our results showed that tagitinin $C$ significantly increased expression of Nrf2 and HO-1 in HCT116 cells at the mRNA level in a concentration-dependent manner at $6 \mathrm{~h}$ after addition of tagitinin $\mathrm{C}$ (Figure 5B). Further, at the concentration of $20 \mu \mathrm{M}$ tagitinin $\mathrm{C}$, mRNA expression level of Nrf2 reached a peak at $4 \mathrm{~h}$ (Figure 5C), and
mRNA expression level of HO-1 was also upregulated by tagitinin $\mathrm{C}$ in a time-dependent manner within $6 \mathrm{~h}$ (Figure 5C). At the same time, we tested the mRNA levels of Nrf2 and HO-1 in HCT116 cells for $24 \mathrm{~h}$ and $48 \mathrm{~h}$ after the treatment of tagitinin $\mathrm{C}$, and the mRNA levels of Nrf2 and HO-1 decreased (Figure S1E-F). This result suggested that Nrf2-HO-1 signaling pathway was activated at early timepoints when treated with tagitinin $\mathrm{C}$, which might play a critical role in inducing ferroptosis within 12 hours.

\section{Tagitinin C induces ER stress, which mediates Nrf2-HO-1 activation}

ER stress can be triggered by natural products and anticancer chemicals [44], including erastin [45], and ER stress plays important role in the cross talk between ferroptosis and other forms of cell death [46]. Here, we showed that tagitinin C-induced ER stress in a time-dependent manner in HCT116 cells (Figure 6A). To investigate whether ER stress was involved in tagitinin C-induced ferroptosis, we used 4-PBA, an ER stress inhibitor, together with tagitinin $C$ to check the cell viability and genes in Nrf2 signaling pathway. As shown in Figure 6B-C, 4-PBA effectively inhibited the tagitinin $\mathrm{C}$-induced cell death and mRNA expression level of Nrf2 and HO-1.

Further, we investigated the key mediator of the tagitinin C-induced ER stress and Nrf2-HO-1 signaling pathway. In previous reports, Nrf2 can be directly phosphorylated by PERK [47]. Our results from western blot assay showed that the abundance of PERK, Nrf2 and HO-1 increased within $12 \mathrm{~h}$ after tagitinin $\mathrm{C}$ treatment (Figure 6D). To investigate whether PERK mediated the activation of Nrf2-HO-1
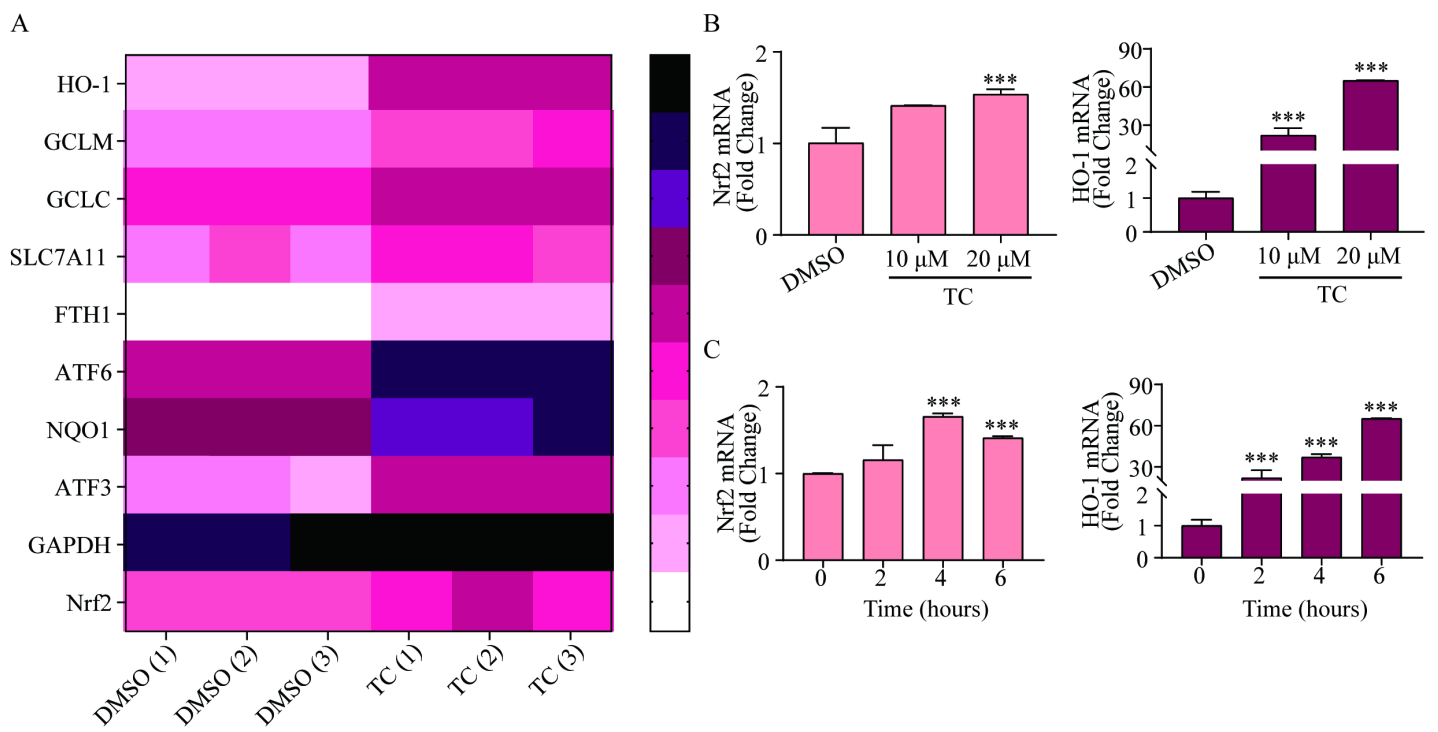

Figure 5. Tagitinin C activates Nrf2-HO-1 signaling pathway. (A) Heat map showed differentially up-regulated genes in response to tagitinin $C$ treatment measured using RNA-seq analysis. Low expression is depicted in white, and high expression is depicted in black. (B-C) Nrf2 and HO-1 mRNA was measured at indicated concentrations or time after treatment of tagitinin C. Data were presented as Mean \pm SD. Statistical analysis was carried out between tagitinin C-treated group and DMSO group: $* p \leq 0.05$, $* * p \leq 0.01, * * * p \leq 0.001$. 
signaling pathway by tagitinin $\mathrm{C}$, we combined GSK2606414 (PERK inhibitor) with tagitinin $C$ in the culture medium of HCT116 cells. The results showed that GSK2606414 decreased tagitinin C-induced cell death (Figure 6E), and also attenuated the upregulation of Nrf2 and HO-1 induced by tagitinin C at both protein and mRNA expression level (Figure $6 \mathrm{~F}-\mathrm{G})$. As mentioned before, Nrf2 is a transcription factor and phosphorylated Nrf2 translocates into the nucleus to transactivate its target genes, including HO-1. As shown in Figure $6 \mathrm{H}$, tagitinin $\mathrm{C}$ upregulated the expression of $\mathrm{Nrf} 2$ in cells and promoted the nuclear translocalization of Nrf2, whereas GSK2606414 significantly inhibited Nrf2 expression as detected by Immunofluorescence (IF). All these results indicated that PERK might be an important mediator of tagitinin C-induced activation of Nrf2-HO-1 signaling pathway.

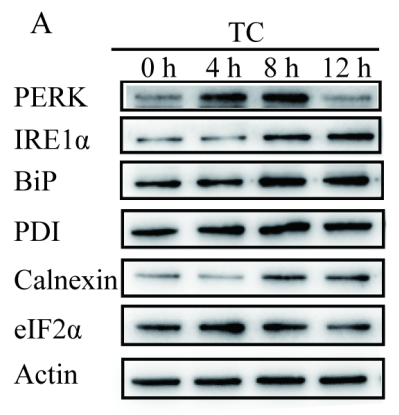

D

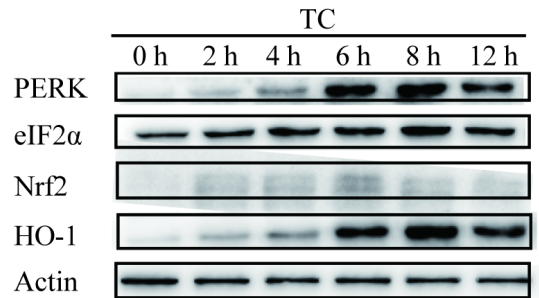

G
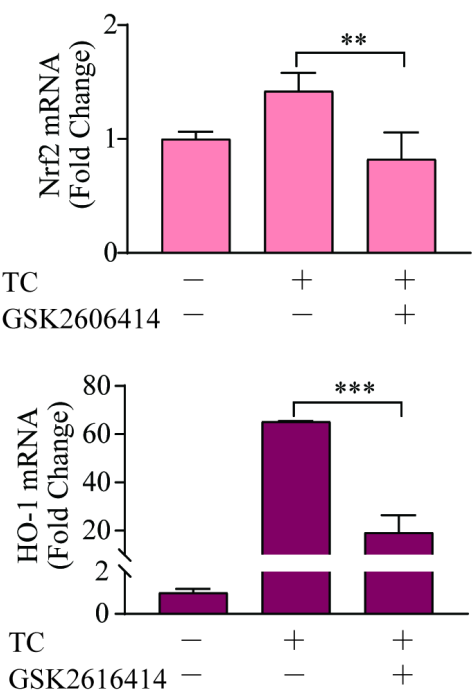

$\mathrm{C}$

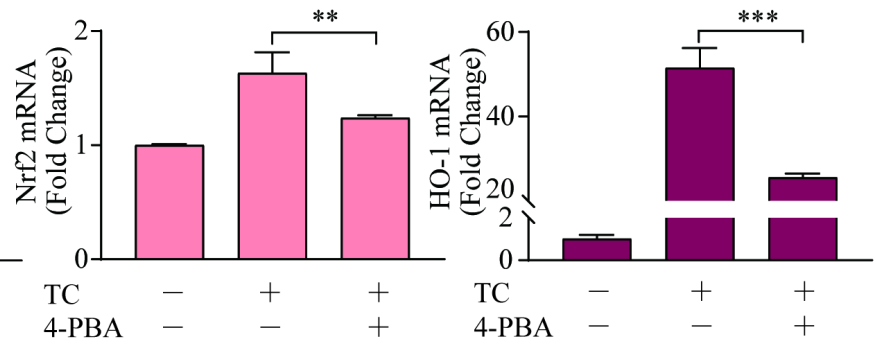

$\mathrm{F}$

$\mathrm{E}$
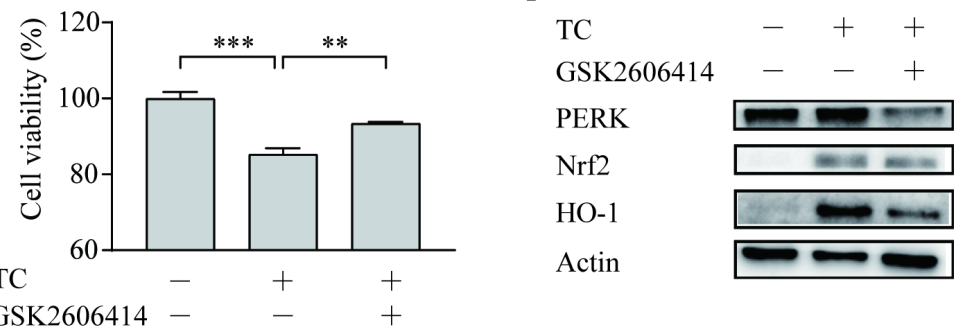

$\mathrm{H}$
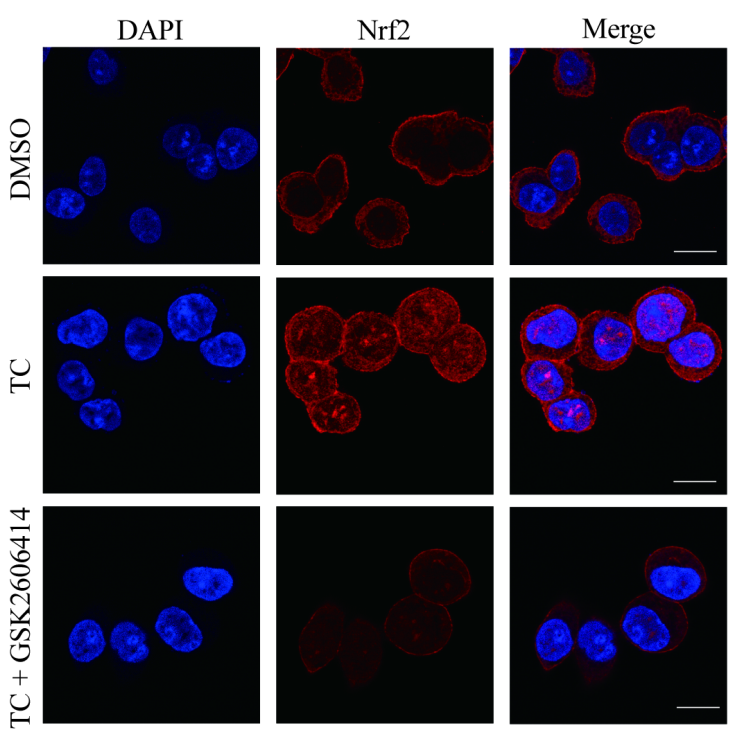

Figure 6. Tagitinin C induces ER stress, which mediates Nrf2-HO-1 activation. (A) HCT116 cells stimulated ER stress. HCT116 cells were treated with $20 \mu M$ tagitinin $\mathrm{C}$ for the indicated time. ER stress-related proteins were determination by Western blot analysis. (B) Cell viability was measured using CCK-8 assay in control cells and cells treated with tagitinin $C(20 \mu \mathrm{M})$ with/without 4-PBA $(20 \mu \mathrm{M})$. (C) HCT116 cells were treated with tagitinin C $(20 \mu \mathrm{M})$ with 4 -PBA $(20 \mu \mathrm{M})$ for $6 \mathrm{~h}$, the cells were collected and used for Nrf2 and HO-1 mRNA determination. (D) HCT116 cells were treated with $20 \mu \mathrm{M}$ tagitinin C for the indicated time intervals. Cells were collected for PERK, elF2a, Nrf2, and HO-1 determination by Western blot analysis. (E) Cell viability was measured using CCK-8 assay in control cells and cells treated with tagitinin $\mathrm{C}$ ( $20 \mathrm{\mu M}$ ) with/without GSK2606414 (5 $\mu \mathrm{M})$. (F) HCT116 cells were treated with $20 \mu \mathrm{M}$ tagitinin $\mathrm{C}$ and/or GSK2606414 for $8 \mathrm{~h}$, the cells were collected and used for Western blot analysis. (G) HCT116 cells were treated with tagitinin C $(20 \mu \mathrm{M})$ with GSK2606414 for $6 \mathrm{~h}$, the cells were collected and used for Nrf2 and HO-1 mRNA determination. (H) HCT116 cells were grown on coverslips and treated with tagitinin C. Tagitinin C-induced Nrf2 nuclear translocation was observed under confocal microscope by IF. Cells were stained with $\mathrm{Nrf2}$ (red) and DAPI (blue) (magnification, $\times 100$ ). Data were presented as Mean \pm SD. Scale bar indicates $100 \mu \mathrm{m}$. Statistical analysis was carried out between tagitinin C-treated group and DMSO group: $* p \leq 0.05, * * p \leq 0.01, * * * p \leq 0.001$. 
A

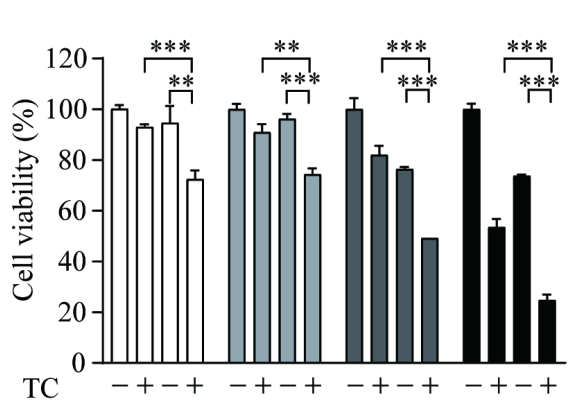

Erastin --++--++--++-++

$\mathrm{C}$

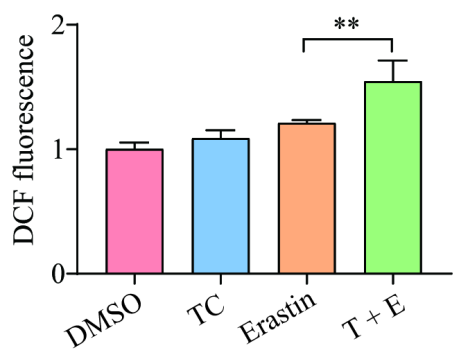

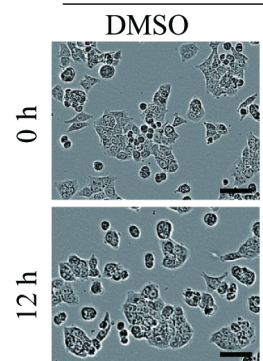
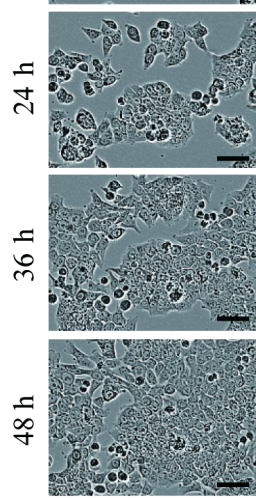

$\mathrm{E}$
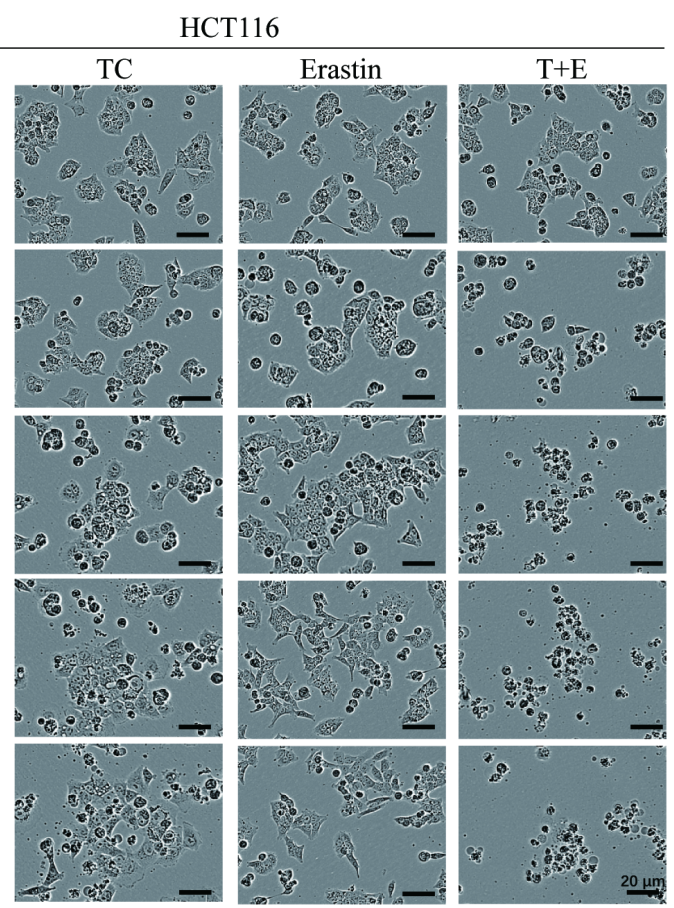

$\mathrm{F}$

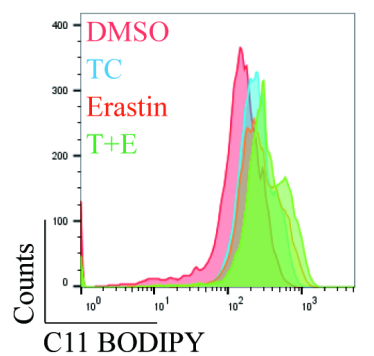

G

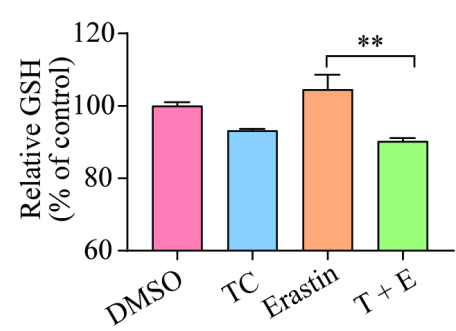

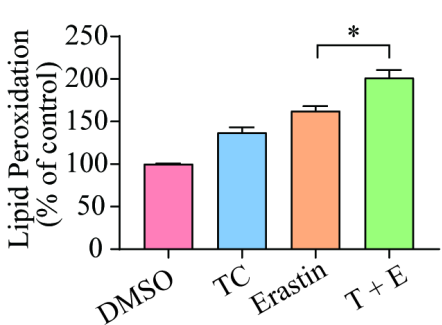

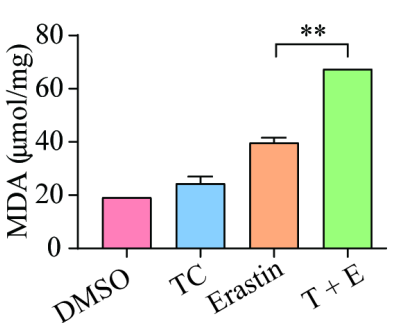

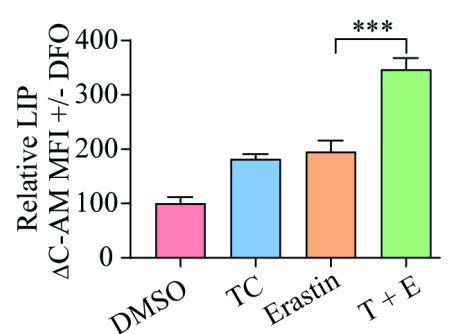

$\mathrm{H}$

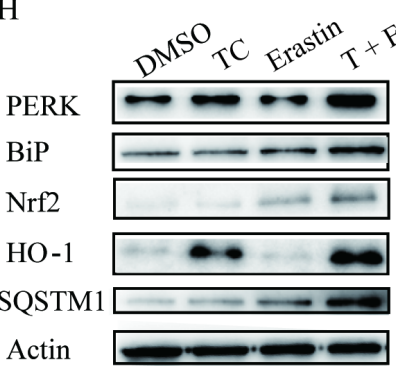

I
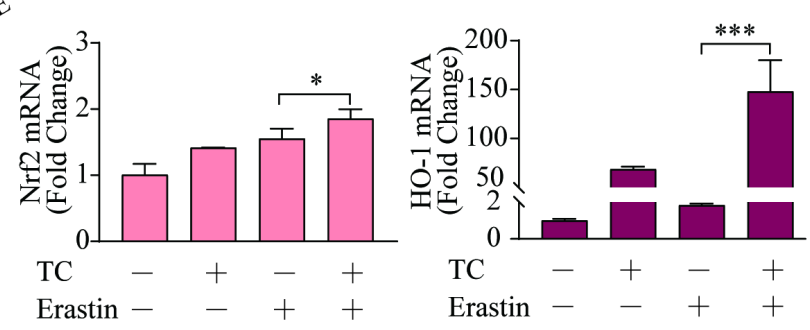

Figure 7. Combination of erastin and tagitinin $\mathbf{C}$ synergistically induces cell death. (A) Cell viability was measured using MTT assay in HCT116 cells treated with tagitinin $C$ with or without erastin at $12,24,36$ and $48 \mathrm{~h}$. (B) The HCT116 cell morphology after treatment with concentration of tagitinin $C$ (10 $\mu M$ ) and/or erastin $(20 \mu M)$ at $0,12,24,36,48 \mathrm{~h}$ (magnification, $\times 10$ ). (C) The contents of the cellular ROS. (D-F) The contents of the cellular lipid peroxidation (D), MDA (E), LIP (F) and GSH (G) in HCT116 cells at $12 \mathrm{~h}$ under tagitinin $\mathrm{C}(10 \mu \mathrm{M})$ and/or erastin $(20 \mu \mathrm{M})$ were determined. $(\mathbf{H}) \mathrm{HCT} 116$ cells were treated with tagitinin $\mathrm{C}(10 \mu \mathrm{M})$ and/or erastin $(20 \mu \mathrm{M})$ for $12 \mathrm{~h}$, the cells were collected and used for Western blot analysis. (I) HCT116 cells were treated with tagitinin C (10 $\mu \mathrm{M})$ and/or erastin $(20 \mu \mathrm{M})$ for $6 \mathrm{~h}$, the cells were collected and mRNA level of Nrf2 and HO-1 were determination. Data were presented as Mean \pm SD. Scale bar indicates $40 \mu \mathrm{m}$. Statistical analysis was carried out between tagitinin C-treated group and DMSO group: $* p \leq 0.05, * * p \leq 0.01, * * * p \leq 0.001$.

\section{Combination of erastin and tagitinin $C$ synergistically induces ferroptotic cell death}

As erastin mainly functions through inhibition of cystine-glutamate reverse to elicit ferroptosis, whereas tagitinin $\mathrm{C}$ may functions through activation of Nrf2-HO-1 signaling pathway. There is possibility that combined treatment of erastin and tagitinin $C$ could enhance tumoricidal efficacy as a novel therapeutic strategy. To investigate whether tagitinin
C combined with erastin could have synergistic effect on cell death induction, we examined the viability of HCT116 cells and their morphological changes after addition of tagitinin $\mathrm{C}(10 \mu \mathrm{M})$ and erastin $(20 \mu \mathrm{M})$ at various time points. The MTT assays revealed that HCT116 cells treated with both compounds exhibited greater growth inhibition (Figure 7A). Compusyn was used to calculate the combination index $(\mathrm{CI})$ values of erastin/tagitinin C cotreatments in HCT116 cells, the 
CI value was 0.72662 when tagitinin $C(10 \mu \mathrm{M})$ and erastin $(20 \mu \mathrm{M})$ was used, which meant moderate synergism [48]. When used alone, erastin had no significant inhibitory effect on the proliferation of HCT116 cells. However, when erastin was used together with tagitinin $C$, cells shrank significantly and lost normal cell morphology (Figure 7B). Similarly, at $12 \mathrm{~h}$ cells treated with erastin or erastin and tagitinin $\mathrm{C}$ showed increases in ROS generation of $21.16 \%$ and $54.36 \%$, respectively (Figure 7C). Consistently, the level of lipid peroxidation, MDA and LIP further increased (Figure 7D-F), whereas the level GSH decreased when treated with both erastin and tagitinin C (Figure 7G). Given that erastin can also induce ER stress, we investigated whether there was a synergistic effect on ER stress induced by erastin in combination with tagitinin $C$. The results indicated that the protein expression levels of PERK and BiP were increased after being treated with the combination of erastin and tagitinin $\mathrm{C}$ (Figure $7 \mathrm{H}$ ). Further, both protein expression levels and mRNA expression levels of Nrf2 and HO-1 were further up-regulated after tagitinin $\mathrm{C}$ and erastin combined treatment (Figure 7I-J). In addition, we found that the expression level of SQSTM1/P62 protein increased significantly under the combined action of tagitinin $\mathrm{C}$ and erastin (Figure $7 \mathrm{H}$ ), which has been reported to activate Nrf2 by degrading Keap1 [49]. This may explain the possible mechanism of the augmented activation of Nrf2-HO-1 signaling pathway by the combined treatment of erastin and tagitinin $\mathrm{C}$. In summary, our results suggested that tagitinin $C$ and erastin can synergistically induce ER stress and activate Nrf2-HO-1 signaling pathway, which leads to cell death, including ferroptosis.

\section{Discussion}

At present, natural plant extracts have been regarded as an important source of anti-tumor drugs due to, not only their diversity of chemical structure and biological activity, but also their reduced overall toxicity and side effects compared to chemosynthetic drugs [50]. Uncovering these categories of natural plant extracts and their functional mechanisms has become one of the research hotspots [51]. Here, we report that tagitinin $\mathrm{C}$, a natural compound isolated from Tithonia diversifolia, exhibited anti-tumor activities in colorectal cancer HCT116 cells. Mechanistically, tagitinin C could induce ferroptosis via ER stress-mediated activation of PERK-Nrf2-HO-1 signaling pathway.

Ferroptosis is a form of cell death mainly induced by intracellular iron accumulation and lipid peroxidation. Excessive iron contributes to ferroptosis through the production of ROS by Fenton reaction; nicotinamide adenine dinucleotide phosphate

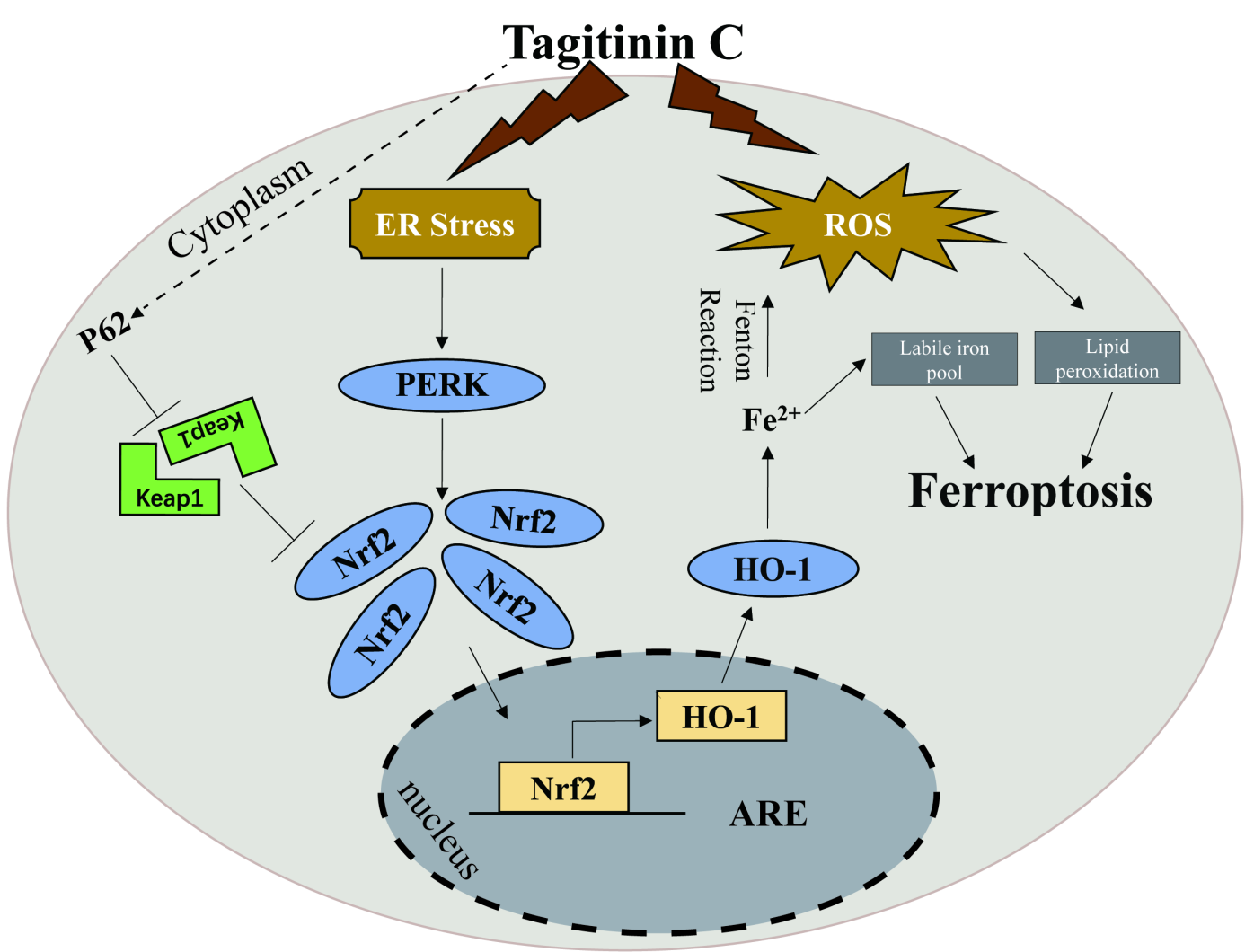

Figure 8. A proposed model showing that tagitinin C induces ferroptosis in HCT116 cells. 
(NADPH)-dependent lipid peroxidation and GSH depletion also play crucial roles in the induction of ferroptosis [52]. Our experimental results demonstrated that the levels of cellular ROS, lipid peroxidation, MDA and the labile iron pool were upregulated, whereas the GSH levels were downregulated in HCT116 cells by treatment of tagitinin C. Meanwhile, we tested the expression levels of the three important regulators of ferroptosis, POR, FSP1 and GPX4 [53-55], the results showed that within 12 hours of tagitinin C treatment in HCT116 cells, the mRNA and protein expression levels of POR were upregulated, while the mRNA expression levels of FSP1 and GPX4 did not change significantly (Figure S1G-H). POR is oxidoreductase which can catalyze the oxidation of phospholipid, which induce membrane damage during ferroptosis. These findings confirmed that tagitinin C-induced ferroptosis contributed to its capability to promote cell death. We evaluated the role of tagitinin $\mathrm{C}$ in a ferroptosis resistant colorectal cancer cell line HCT116 [56]. It has been reported that HCT116 exhibit resistance to ferroptosis may through p53-dependent and p53-independent ways [56-58]. Whether tagitinin $C$ induce ferroptosis through p53 signaling pathway needs further evaluation.

By RNA-seq analysis of tagitinin C treated cells, we identified HO-1 as a possible target of tagitinin $\mathrm{C}$. $\mathrm{HO}-1$ is an endoplasmic reticulum (ER)-anchored enzyme that metabolizes heme into pro-oxidant ferrous iron, carbon monoxide and anti-oxidant biliverdin. HO-1 shows cytoprotective effects against various stress-related conditions [59]. However, increasing numbers of studies have shown that high expression of HO-1 is an important positive regulator of ferroptosis which makes it an important candidate to mediate detrimental effects such as ferroptosis induction [60]. Betulaceae extract induced ferroptosis in human colon cancer cells via the triggering of HO-1 expression [61]. Erastin-induced ferroptotic cell death could be accelerated by HO-1 in HT-1080 fibrosarcoma cells and BAY 11-7085-induced ferroptosis was also mediated by HO-1 in breast cancer cells [62,63]. Doxorubicin-induced ferroptosis in cardiomyocytes was also mediated by heme degradation, a result of Nrf2-mediated upregulation of HO-1 [64]. Withaferin A (WA), a natural ferroptotic agent, also induce ferroptosis in neuroblastoma by promoting iron accumulation and ROS production via HO-1 high expression [65]. All these findings showed that the ferroptotic cell death can be induced by HO-1 through regulation of the amount of cellular iron and ROS. Apparently, HO-1 plays dual role in iron and ROS homeostasis, as well as ferroptosis induction, including cytoprotective effects or detrimental effects. Similar with the ferroptosis inducers mentioned above, tagitinin $\mathrm{C}$ also induced high expression of HO-1 within 6 hours, which led to cellular iron accumulation and ferroptosis. Thus, tagitinin $\mathrm{C}$ also functions as a ferroptosis inducer mainly through activation of Nrf2-HO-1 signaling pathway.

Production of ROS has been linked to ER stress $[66,67]$. The endoplasmic reticulum (ER) is a specialized organelle for regulation of protein synthesis, folding, secretion, or posttranslational modification. In response to microenvironmental stimuli, protein misfolding in the ER occurs and accumulates, a process known as ER stress [68]. To cope with ER stress, cancer cells initiate an unfolded protein response (UPR) through three different signaling pathways including PERK pathway. PERK is phosphorylated and activated by BiP $[69,70]$, which subsequently phosphorylated Nrf2, a transcription factor. The latter dissociates from Nrf2/Keap1 complexes in the cytoplasm and then translocates into the nucleus, where Nrf2 interacts with antioxidant response element (ARE) and transactivates various genes, including HO-1, GCLM, SLC7A11, GCLC, FTH1, ATF6, NQO1, GAPDH and ATF3, as well as Nrf2 itself [71]. Both ER stress and UPR are documented to be involved with the development of cancer and play an important role in ferroptosis [72,73]. In our study, tagitinin C could induce ER stress, which lead to activation of PERK signaling pathway. ER stress inhibitor or PERK inhibitor effectively inhibited tagitinin C-induced cell death and activation of Nrf2-HO-1 signaling pathway. Besides ferroptosis, tagitinin $\mathrm{C}$ also induced apoptosis at later time points. Lipid peroxidation is a hallmark of ferroptosis. An excess of ROS, which propagates lipid peroxidation chain, also attacks biomembranes and subsequently leads to different types of cell death [74]. ER stress has been reported to play important roles in the crosstalk between ferroptosis and apoptosis [75]. ER stress-mediated activation of PERK-eIF2a-ATF4-CHOP pathway has been reported to induce both apoptosis and ferroptosis. Here, whether tagitinin C-induced ferroptosis and apoptosis is through the ER stress-mediated PERK signaling pathway needs further investigation.

Combined treatment of tagitinin $\mathrm{C}$ together with a well-known ferroptosis inducer, erastin, showed synergistic effects on cytotoxicity, including ferroptosis. Mechanistically, the effect caused by tagitinin $\mathrm{C}$ in inducing ferroptosis could be further amplified by erastin since erastin could also stimulate ER stress. The tumoricidal efficacy was enhanced by the combined treatment of tagitinin $\mathrm{C}$ and erastin, rendering ferroptosis insensitive HCT116 cells susceptible to ferroptotic cell death. In addition, we found tagitinin $\mathrm{C}$ also had synergistic cytotoxicity 
with ferroptosis inducer RSL3 (Figure S1I). This might provide insight into novel therapeutic strategy to overcome drug resistance in cancer.

In summary, in this study, we found that tagitinin $\mathrm{C}$ could induce ferroptosis by inducing ROS and stimulating ER stress, which leads to activation of PERK-Nrf2-HO-1 signaling pathway in HCT116 cells.

\section{Supplementary Material}

Supplementary figures.

http://www.ijbs.com/v17p2703s1.pdf

\section{Acknowledgments}

This research was supported financially by grants from the National Natural Science Foundation of China (32000548, 82073740 and 81703393), Natural Science Foundation of Yunnan Province (202001AT070053 and 202001AT070055), grants of State Key Laboratory of Phytochemistry and Plant Resources in West China (P2018-ZZ05 and P2019-ZZ06) and National Natural Science Foundation of China (U1812403). This study was also supported by shared resources of the Service Center for Bioactivity Screening, State Key Laboratory of Phytochemistry and Plant Resources in West China. The authors would like to thank Dr. Qinghua Kong, Hongmei Li, Lian Yang for their technical assistance.

\section{Competing Interests}

The authors have declared that no competing interest exists.

\section{References}

1. Brody H, Grayson M, Miller K, Bender E, Haines N. Colorectal cancer. Nature. 2015; 521: S1.

2. Weitz J, Koch M, Debus J, Höhler T, Galle PR, Büchler MW. Colorectal cancer. Lancet. 2005; 365: 153-165.

3. Ganesh K, Stadler ZK, Cercek A, Mendelsohn RB, Shia J, Segal NH, Diaz LA Jr. Immunotherapy in colorectal cancer: rationale, challenges and potential. Nature Reviews Gastroenterology \& Hepatology. 2019; 16: 361-375.

4. Kopetz S. New therapies and insights into the changing landscape of colorectal cancer. Nature Reviews Gastroenterology \& Hepatology. 2019; 16: $79-80$

5. Dixon SJ, Lemberg KM, Lamprecht MR, Skouta R, Zaitsev EM, Gleason CE, et al. Ferroptosis: An iron-dependent form of nonapoptotic cell death. Cell. 2012; 149: 1060-1072.

6. Dixon SJ, Stockwell BR. The role of iron and reactive oxygen species in cell death. Nature Chemical Biology. 2014; 10: 9-17.

7. Zhou YL, Shen $Y$, Chen $C$, Sui XB, Yang JJ, Wang LB, et al. The crosstalk between autophagy and ferroptosis: What can we learn to target drug resistance in cancer? Cancer Biology and Medicine. 2019; 16: 630-646.

8. Gao M, Deng J, Liu F, Fan P, Wang YJ, Wu HY, et al. Triggered ferroptotic polymer micelles for reversing multidrug resistance to chemotherapy. Biomaterials. 2019; 223: 119486

9. Kim EH, Shin D, Lee J, Jung AR, Roh J. CISD2 inhibition overcomes resistance to sulfasalazine-induced ferroptotic cell death in head and neck cancer. Cancer Letters. 2018; 432: 180-190.

10. Elgendy SM, Alyammahi SK, Alhamad DW, Abdin SM, Omar HA. Ferroptosis: An emerging approach for targeting cancer stem cells and drug resistance. Critical Reviews in Oncology/Hematology. 2020; 15: 103095.

11. Wang WM, Green M, Choi JE, Gijon M, Kennedy PD, Johnson JK, et al. CD8+ $\mathrm{T}$ cells regulate tumour ferroptosis during cancer immunotherapy. Nature. 2019; 569: 270-274.

12. Shibata Y, Yasui H, Higashikawa K, Miyamoto N, Kuge Y. Erastin, a ferroptosis-inducing agent, sensitized cancer cells to $\mathrm{X}$-ray irradiation via glutathione starvation in vitro and in vivo. Plos One. 2019; 14: e0225931.
13. Jiang YQ, He YC, Liu S, Tao YG. Chromatin remodeling factor lymphoidspecific helicase inhibits ferroptosis through lipid metabolic genes in lung cancer progression. Chinese Journal of Cancer. 2017; 36.

14. Chen GQ, Benthani FA, Wu J, Liang DG, Bian ZX, Jiang XJ. Artemisinin compounds sensitize cancer cells to ferroptosis by regulating iron homeostasis. Cell Death and Differentiation. 2020; 27: 242-254.

15. Bailly C. Anticancer activities and mechanism of action of nagilactones, a group of terpenoid lactones isolated from podocarpus species. Natural Products and Bioprospecting. 2020; 10: 367-375.

16. Song ZW, Xiang XJ, Li JH, Deng J, Fang ZL, Zhang L, et al. Ruscogenin induces ferroptosis in pancreatic cancer cells. Oncology Reports. 2020; 43: 516-524.

17. Chen Y, Li N, Wang HJ, Wang NN, Peng H, Wang J, et al. Amentoflavone suppresses cell proliferation and induces cell death through triggering autophagy-dependent ferroptosis in human glioma. Life Sciences. 2020; 247: 117425 .

18. Khorsandi K, Kianmehr Z, Hosseinmardi Z, Hosseinzadeh R. Anti-cancer effect of gallic acid in presence of low level laser irradiation: ROS production and induction of apoptosis and ferroptosis. Cancer Cell International, 2020; 20: $18-32$.

19. Wu CY, Lin YS, Shen YC, Tsai YY, Yang YH, Lin YY, et al. Danshen improves survival of patients with breast cancer and dihydroisotanshinone I induces ferroptosis and apoptosis of breast cancer cells. Frontiers in Pharmacology. 2019; 10: 1226

20. Ranti I, Wahyuningsih MSH, Wirohadidjojo YW. The antifibrotic effect of isolate tagitinin C from tithonia diversifolia (Hemsley) A. Gray on keloid fibroblast cell. Pan African Medical Journal. 2018; 30: 264

21. Liao MH, Lin WC, Wen HC, Pu HF. Tithonia diversifolia and its main active component tagitinin $\mathrm{C}$ induce survivin inhibition and $\mathrm{G} 2 / \mathrm{M}$ arrest in human malignant glioblastoma cells. Fitoterapia. 2011; 82: 331-341.

22. Zhao LH, Dong JH, Hu ZH, Li SL, Su XX, Zhang J, et al. Anti-TMV activity and functional mechanisms of two sesquiterpenoids isolated from Tithonia diversifolia. Pesticide Biochemistry and Physiology. 2017; 140: 24-29.

23. Gonçalves-Santos E, Vilas-Boas DF, Diniz LF, Veloso MP, Mazzeti AL, Rodrigues MR, et al. Sesquiterpene lactone potentiates the immunomodulatory, antiparasitic and cardioprotective effects on anti-Trypanosoma cruzi specific chemotherapy. International Immunopharmacology. 2019; 77: 105961.

24. Lee MY, Liao MH, Tsai YN, Chiu KH, Wen HC. Identification and anti-human glioblastoma activity of tagitinin $\mathrm{C}$ from tithonia diversifolia methanolic extract. Journal of Agricultural and Food Chemistry. 2011; 59: 2347-2355.

25. Liao MH, Tsai YN, Yang CY, Juang CL, Lee MY, Chang LH, et al. Anti-human hepatoma Hep-G2 proliferative, apoptotic, and antimutagenic activity of tagitinin C from Tithonia diversifolia leaves. Journal of Natural Medicines. 2013; 67: 98-106.

26. Yu Y, Xie YC, Cao LZ, Yang LC, Yang MH, Lotze M, et al. The ferroptosis inducer erastin enhances sensitivity of acute myeloid leukemia cells to chemotherapeutic agents. Molecular \& Cellular Oncology. 2015; 2: e1054549.

27. Wu J, Minikes AM, Gao M, Bian $\mathrm{H}$, Li $\mathrm{Y}$, Stockwell BR, et al. Intercellular interaction dictates cancer cell ferroptosis via NF2-YAP signalling. Nature, 2019; 572: 402-406.

28. Das I, Gad H, Brautigam L, Pudelko L, Tuominen R, Hoiom V, et al. AXL and CAV-1 play a role for MTH1 inhibitor TH1579 sensitivity in cutaneous malignant melanoma. Cell Death \& Differentiation, 2020; 27: 2081-2098.

29. Rahayu F, Tajima T, Kato J, Kato S, Nakashimada Y. Ethanol yield and sugar usability in thermophilic ethanol production from lignocellulose hydrolysate by genetically engineered Moorella thermoacetica. Journal of Bioscience and Bioengineering, 2020; 129: 160-164.

30. Lohcharoenkal W, Harada M, Lovén J, Meisgen F, Landén NX, Zhang L, et al. MicroRNA-203 inversely correlates with differentiation grade, targets c-MYC, and functions as a tumor suppressor in CSCC. Journal of Investigative Dermatology, 2016; 136: 2485-2494.

31. Chu J, Liu CX, Song R, Li QL. Ferrostatin-1 protects HT-22 cells from oxidative toxicity. Neural Regeneration Research. 2020; 15: 528-536.

32. Duscher D, Januszyk M, Maan ZN, Whittam AJ, Hu MS, Walmsley GG, et al. Comparison of the hydroxylase inhibitor dimethyloxalylglycine and the iron chelator deferoxamine in diabetic and aged wound healing. Plastic and Reconstructive Surgery. 2017; 139: 695-706.

33. Yang WS, Stockwell BR. Ferroptosis: Death by lipid peroxidation. Trends in Cell Biology. 2016; 26: 145-176.

34. Wang H, An P, Xie EJ, Wu Q, Fang XX, Gao H, et al. Characterization of ferroptosis in murine models of hemochromatosis. Hepatology. 2017; 66: 449-465.

35. Doll S, Conrad M. Iron and ferroptosis: A still ill-defined liaison. IUBMB Life. 2017; 69: 423-434

36. Kakhlon O, Cabantchik ZI. The labile iron pool: Characterization, measurement, and participation in cellular processes. Free Radical Biology \& Medicine. 2002; 33: 1037-1046.

37. Su LJ, Zhang JH, Gomez H, Murugan R, Hong X, Xu DX, et al. Reactive oxygen species-induced lipid peroxidation in apoptosis, autophagy, and ferroptosis. Oxidative Medicine and Cellular Longevity. 2019; 2019: 1-13.

38. Halasi M, Wang M, Chavan TS, Gaponeko V, Hay N, Gartel AL. ROS inhibitor $\mathrm{N}$-acetyl-L-cysteine antagonizes the activity of proteasome inhibitors. Biochemical Journal. 2013; 454: 201-208.

39. Ursini F, Maiorino M. Lipid peroxidation and ferroptosis: The role of GSH and GPX4. Free Radical Biology \& Medicine. 2020; 152: 175-185. 
40. Gao MH, Yi JM, Zhu JJ, Minikes AM, Monian P, Thompson CB, et al. Role of mitochondria in ferroptosis. Molecular Cell. 2019; 73: 354-363.

41. Kanzaki H, Shinohara F, Kajiya M, Kodama T. The Keap1/Nrf2 protein axis plays a role in osteoclast differentiation by regulating intracellular reactive oxygen species signaling. Journal of Biological Chemistry. 2013; 288: 23009-23020.

42. Itoh K, Mimura J, Yamamoto M. Discovery of the negative regulator of Nrf2, Keap1: A historical overview. Antioxidants \& Redox Signaling. 2010; 13: 1665-1678.

43. Furfaro AL, Traverso N, Domenicotti C, Piras S, Moretta L, Marinari UM, et al. The Nrf2/HO-1 axis in cancer cell growth and chemoresistance. Oxidative Medicine and Cellular Longevity. 2016; 2016: 1958174.

44. Pereira DM, Valentao P, Correia-da-Silva G, Teixeira N, Andrade PB. Translating endoplasmic reticulum biology into the clinic: A role for ER-targeted natural products? Natural Product Reports. 2015; 32: 705-722.

45. Dixon SJ, Patel DN, Welsch M, Skouta R, Lee ED, Hayano M, et al. Pharmacological inhibition of cystine-glutamate exchange induces endoplasmic reticulum stress and ferroptosis. eLife. 2014; 3.

46. Lee Y, Lee D, Choudry HA, Bartlett DL, Lee YJ. Ferroptosis-induced endoplasmic reticulum stress: Cross-talk between ferroptosis and apoptosis. Molecular Cancer Research. 2018; 16: 1073-1076.

47. Cullinan SB, Zhang D, Hannink M, Arvisais E, Kaufman RJ, Alan Diehl J. Nrf2 is a direct PERK substrate and effector of PERK-dependent cell survival. Molecular and Cellular Biology. 2003; 23: 7189-209.

48. Banerjee V, Sharda N, Huse J, Singh D, Sokolov D, Czinn SJ, Thomas-G C, Blanchard, Banerjee A. Synergistic potential of dual andrographolide and melatonin targeting of metastatic colon cancer cells: Using the Chou-Talalay combination index method. European Journal of Pharmacology. 2021; 15: 173919.

49. Bae SH, Sung SH, Lim JM, Lee SK, Park YN, Lee HE, et al. Sestrins activate Nrf2 by promoting P62-dependent autophagic degradation of Keap1 and prevent oxidative liver damage. Cell Metabolism. 2013; 17: 73-84.

50. Newman DJ, Cragg GM. Natural products as sources of new drugs over the nearly four decades from 01/1981 to 09/2019. Journal of Natural Products. 2020; 83: 770-803.

51. Cragg GM, Grothaus PG, Newman DJ. Impact of natural products on developing new anti-cancer agents. Chemical Reviews. 2009; 109: 3012-3043.

52. Hassannia B, Vandenabeele P, Berghe TV. Targeting ferroptosis to iron out cancer. Cancer Cell. 2019; 35: 830-849.

53. Yan B, Ai YW, Sun Q, Ma Y, Cao Y, Wang JW, Zhang ZY, Wang XD. Membrane damage during ferroptosis is caused by oxidation of phospholipids catalyzed by the oxidoreductases POR and CYB5R1. Molecular Cell. 2021; 81: 355-369.

54. Esuker K, Hendricks JM, Li ZP, Magtanong L, Ford B, Tang PH, Roberts MA, Tong BQ, Maimone TJ, Zoncu R, Bassik M, Nomura DK, Dixon SJ, Olzmann JA. The CoQ oxidoreductase FSP1 acts parallel GPX4 to inhibit ferroptosis. Nature. 2019; 575: 688-692.

55. Yang WS, SriRamaratnam R, Welsch ME, Shimada K, Skouta R, Viswanathan VS, Cheah JH, Clemons PA, Shamji AF, Clish CB, Brown LM, Girotti AW, Cornish VW, Schreiber SL, Stockwell BR. Regulation of ferroptotic cancer cell death by GPX4. Cell. 2014; 156: 317-331.

56. Venkatesh D, Stockwell BR, Prives C. p21 can be a barrier to ferroptosis independent of p53. Aging (Albany NY), 2020; 12: 17800-17814.

57. Xie Y, Zhu S, Song X, Sun X, Fan Y, Liu J, et al. The tumor suppressor p53 limits ferroptosis by blocking DPP4 activity. Cell Reports. 2017; 20: 1692-1704.

58. Chu B, Kon N, Chen D, Li T, Liu T, Jiang L, et al. ALOX12 is required for p53-mediated tumour suppression through a distinct ferroptosis pathway. Nature Cell Biology. 2019; 21: 579-591.

59. Gottlieb Y, Truman M, Cohen LA, Leichtmann-Bardoogo Y, Meyron-Holtz EG. Endoplasmic reticulum anchored heme-oxygenase 1 faces the cytosol. Haematologica. 2012; 97: 1489-1493.

60. Chiang S, Chen S, Chang LC. A dual role of heme oxygenase-1 in cancer cells. International Journal of Molecular Sciences. 2019; 20: 39.

61. Malfa GA, Tomasello B, Acquaviva R, Genoves C, Mantia AL, Cammarata FP, et al. Betula etnensis Raf. (Betulaceae) extract induced HO-1 expression and ferroptosis cell death in human colon cancer cells. International Journal of Molecular Sciences. 2019; 20: 2723.

62. Kwon MY, Park E, Lee SJ, Chung SW. Heme oxygenase-1 accelerates erastin-induced ferroptotic cell death. Oncotarget. 2015; 6: 24393-24403.

63. Chang LC, Chiang SK, Chen SE, Yu YL, Chou RH, Chang WC. Heme oxygenase-1 mediates BAY 11-7085 induced ferroptosis. Cancer Letters. 2018; 416: 124-137.

64. Fang XX, Wang H, Han D, Xie EJ, Yang X, Wei JY, et al. Ferroptosis as a target for protection against cardiomyopathy. Proceedings of the National Academy of Sciences. 2019; 116: 2672-2680.

65. Hassannia B, Wiernicki B, Ingold I, Herck SV, Tyurina $\mathrm{Y}$, Bayir $\mathrm{H}$, et al. Nano-targeted induction of dual ferroptotic mechanisms eradicates high-risk neuroblastoma. The Journal of Clinical Investigation. 2018; 128: 3341-3355.

66. Zeeshan $\mathrm{H}$, Lee $\mathrm{GH}$, Kim H, Chae H. Endoplasmic reticulum stress and associated ROS. International Journal of Molecular Sciences. 2016; 17: 327.

67. Cao SS, Kaufman RJ. Endoplasmic reticulum stress and oxidative stress in cell fate decision and human disease. Antioxidants \& Redox Signaling. 2014; 21: 396-413.
68. Wang M, Kaufman RJ. The impact of the endoplasmic reticulum proteinfolding environment on cancer development. Nature Reviews Cancer. 2014; 14: 581-597.

69. Bertolotti A, Zhang YH, Hendershot LM, Harding HP, Ron D. Dynamic interaction of Bip and ER stress transducers in the unfolded-protein response. Nature Cell Biology. 2000; 2: 326-332.

70. Cook KL, Soto-Pantoja DR, Clarke PG, Zwart A, Warri, A, Hilakivi-Clarke L, et al. Endoplasmic reticulum stress protein GRP78 modulates lipid metabolism to control drug sensitivity and antitumor immunity in breast cancer. Cancer Research. 2016; 76: 5657-5670.

71. Qaisiya M, Zabetta CC, Bellarosa C, Tiribelli C. Bilirubin mediated oxidative stress involves antioxidant response activation via Nrf2 pathway. Cellular Signaling. 2014; 26: 512-520.

72. Sano R, Reed JC. ER stress-induced cell death mechanisms. Biochimica et Biophysica Acta. 2013; 1833: 3460-3470.

73. Häcker G. ER-stress and apoptosis: molecular mechanisms and potential relevance in infection. Microbes and Infection. 2014; 16: 805-810.

74. Su LJ, Zhang JH, Gomez H, Murugan R, Hong X, Xu D, et al. Reactive oxygen species-induced lipid peroxidation in apoptosis, autophagy, and ferroptosis. Oxidative Medicine and Cellular Longevity. 2019; 5080843.

75. Lee YS, Lee DH, Choudry HA, Bartlett DL, Lee YJ. Ferroptosis-induced endoplasmic reticulum stress: cross-talk between ferroptosis and apoptosis. Molecular Cancer Research. 2018; 16: 1073-1076. 